\title{
THE LONG-TERM PERFORMANCE OF INITIAL PUBLIC OFFERINGS ON EUROPE'S NEW STOCK MARKETS
}

Article in Advances in Financial Economics · November 2004

DOI: 10.1016/S1569-3732(04)10012-1

CITATIONS

3

2 authors, including:

\section{Giancarlo Giudici}

Politecnico di Milano

29 PUBLICATIONS 326 CITATIONS

SEE PROFILE
READS

11 

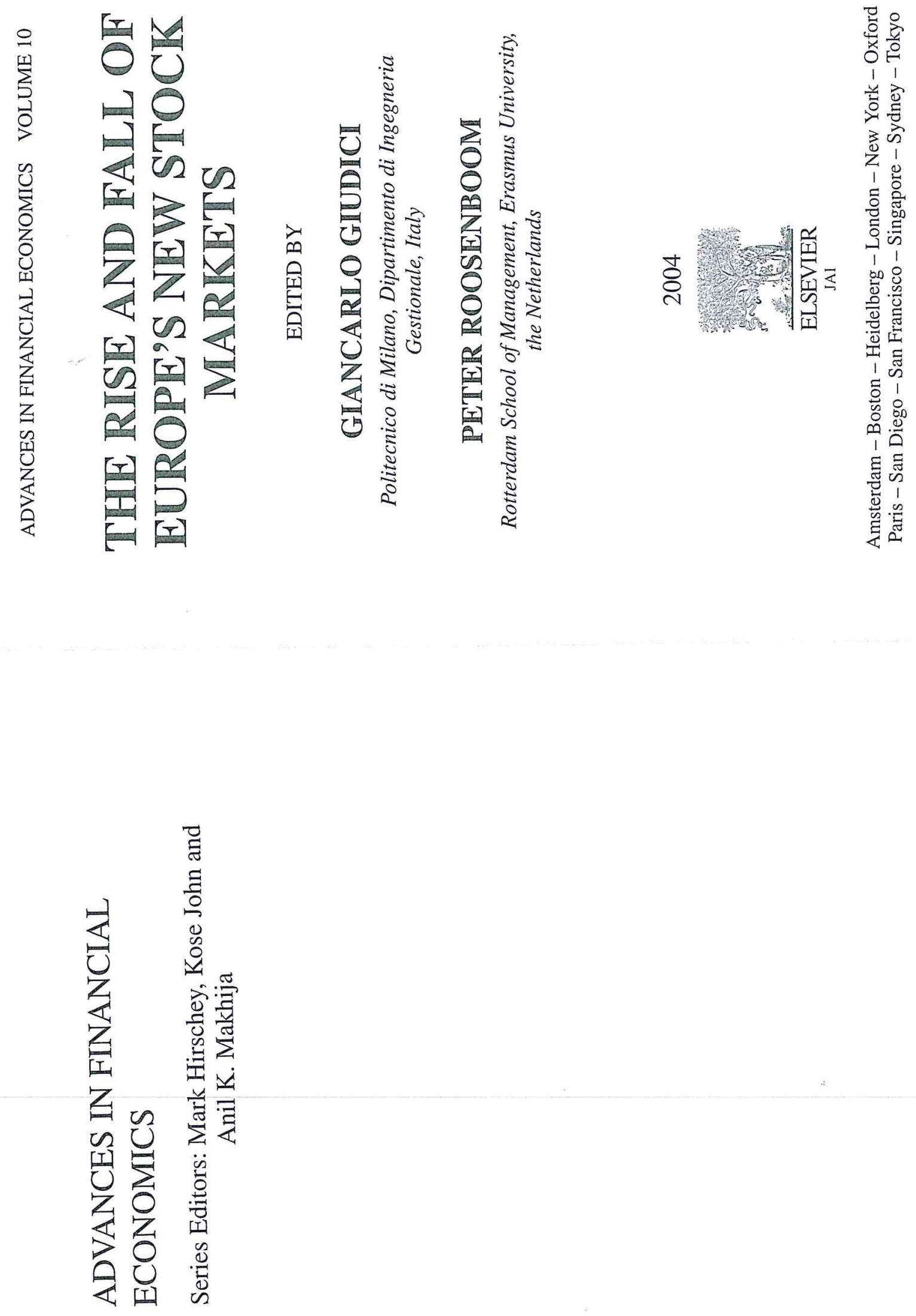

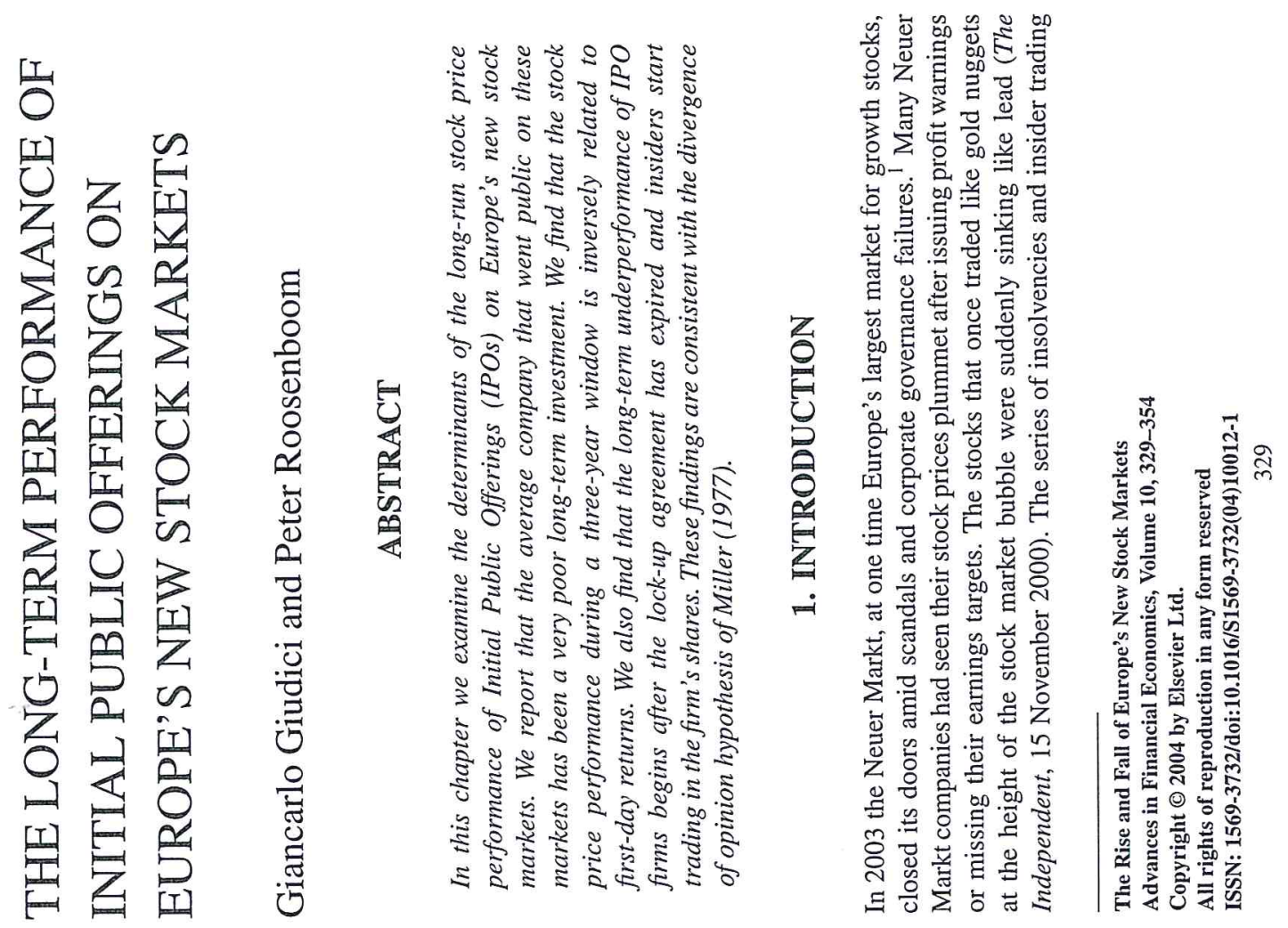


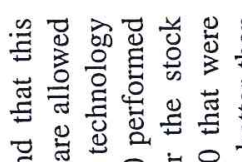

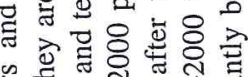
년 ษั क्ष

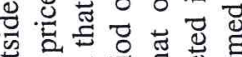

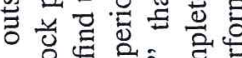

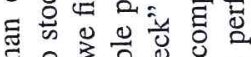

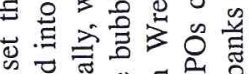
啳

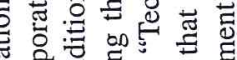

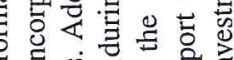

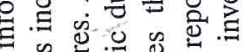

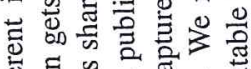

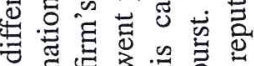

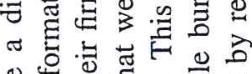

宕峞 总总密 o d 政 品

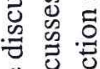

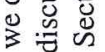
总言 돈 远 I क क

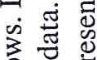
을 要远 要 苟 (용

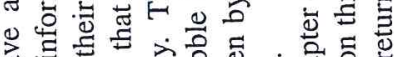

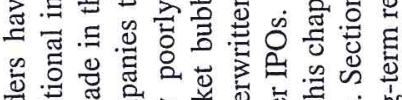

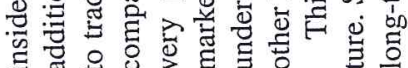

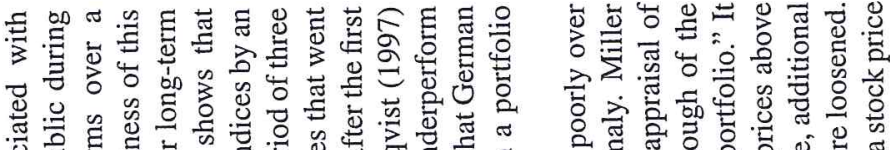

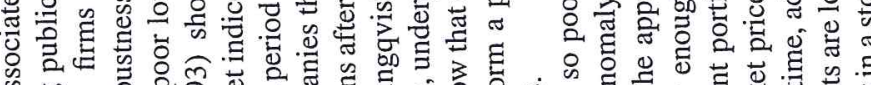
की

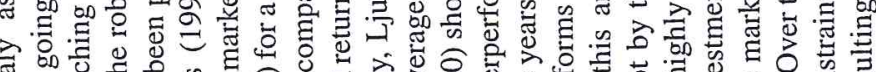

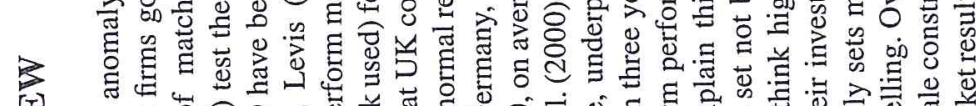

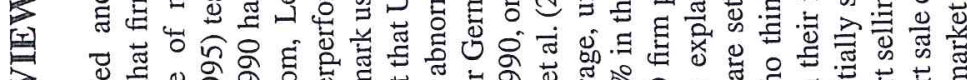
むँ

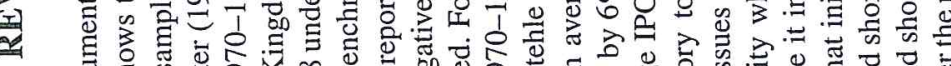

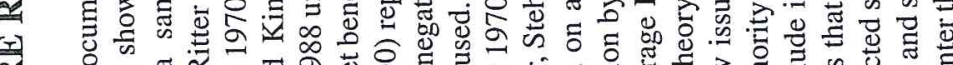

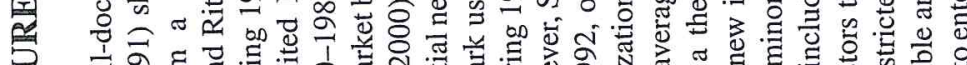

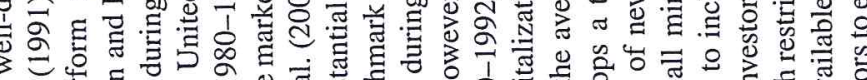

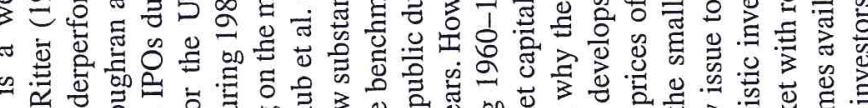

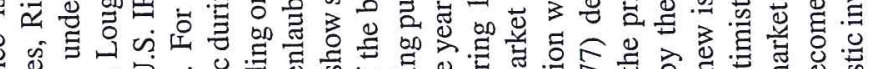

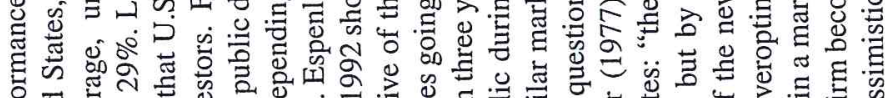

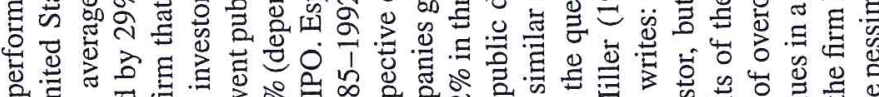

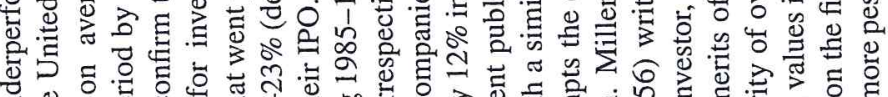

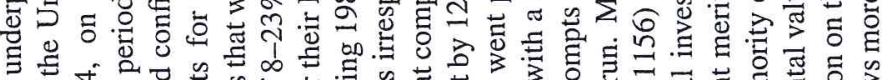

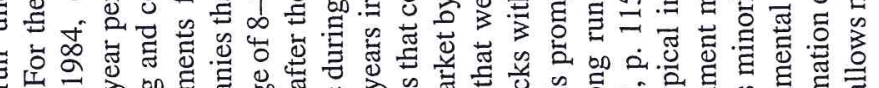

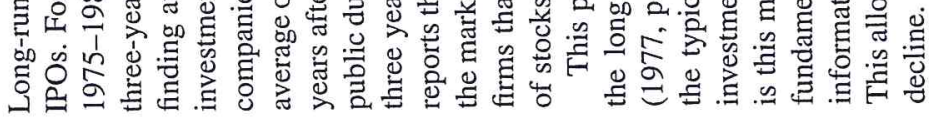

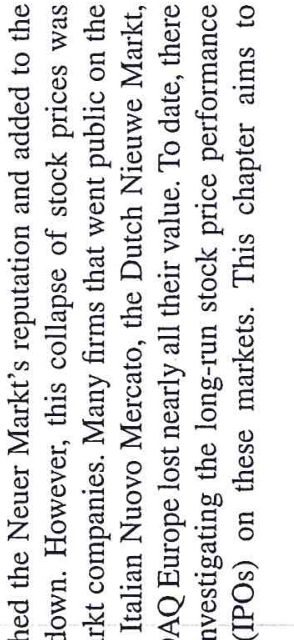

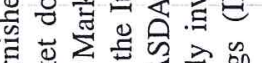

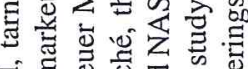

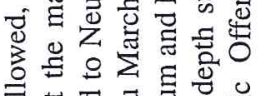

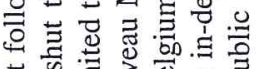

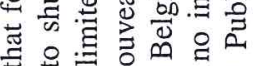

ڤ.⿻日乚

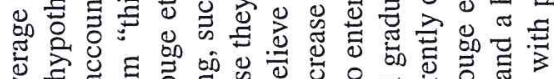

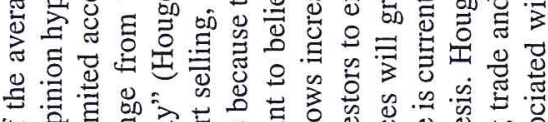

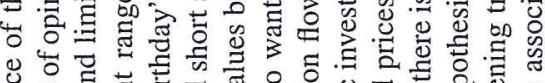

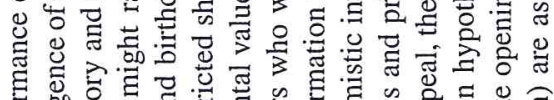

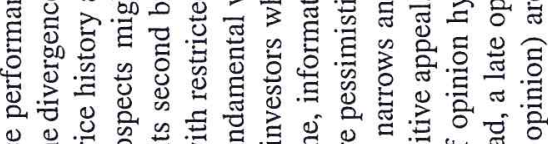

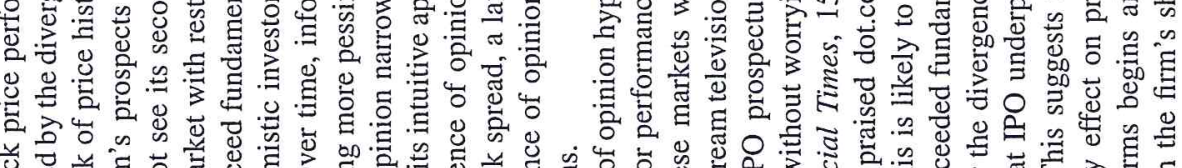

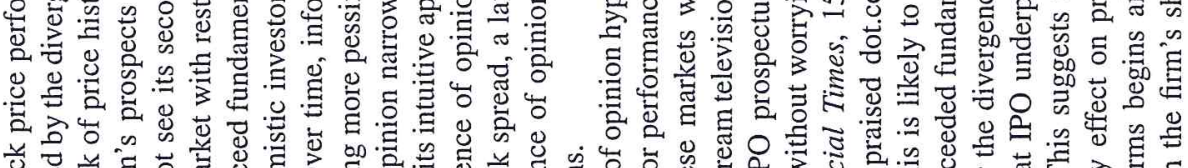

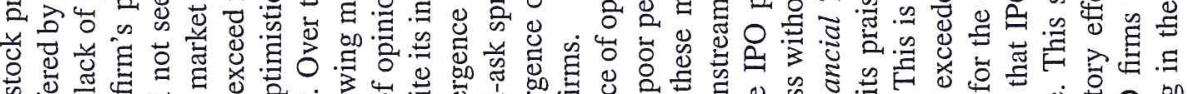

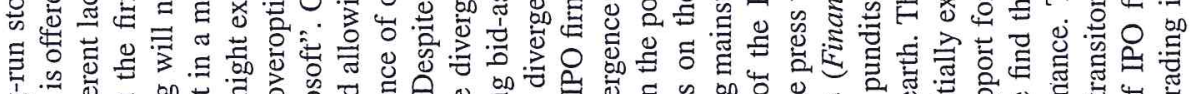

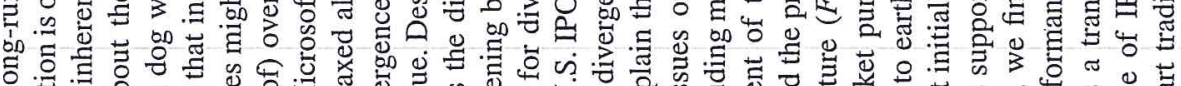

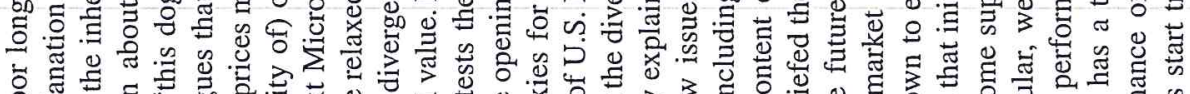

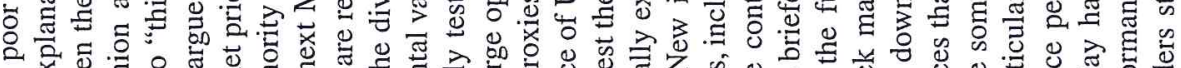

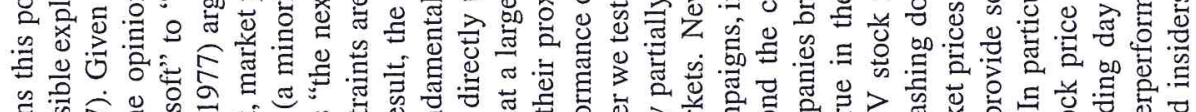

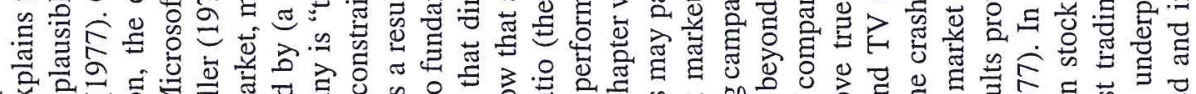

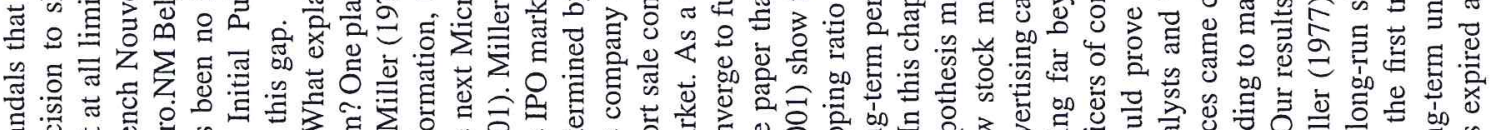

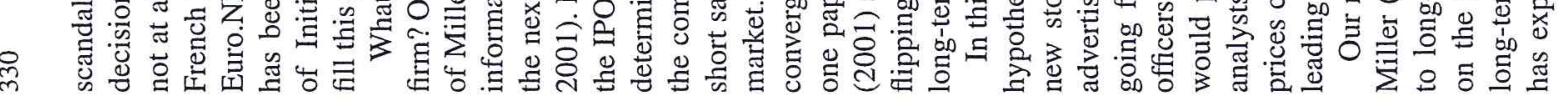




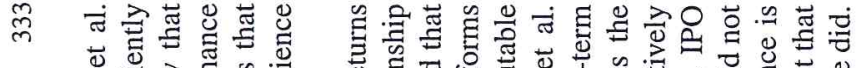

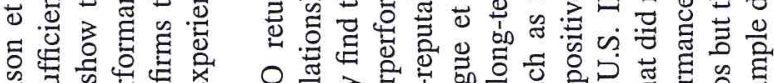

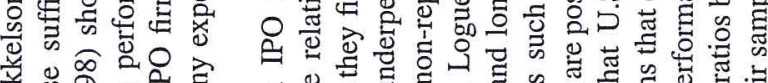

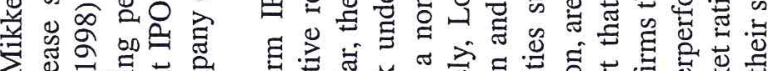

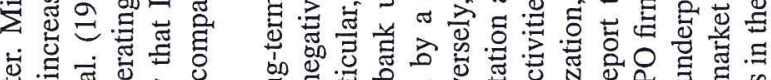

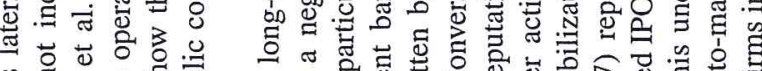

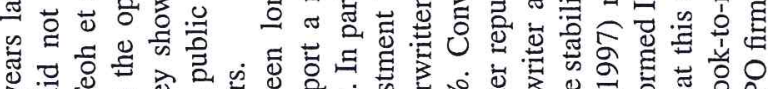

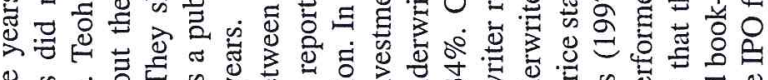

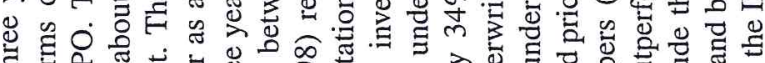

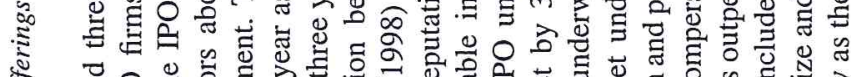

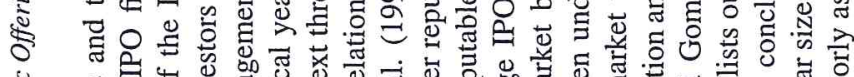

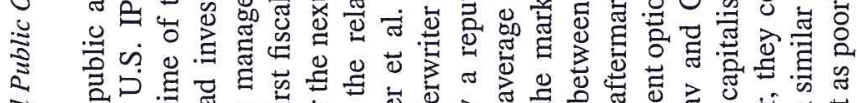

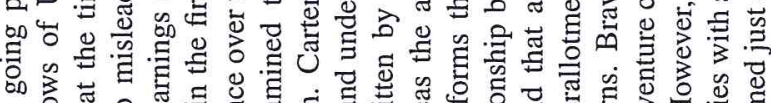

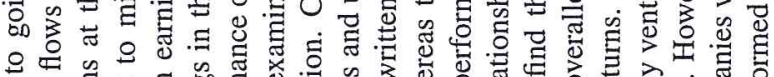

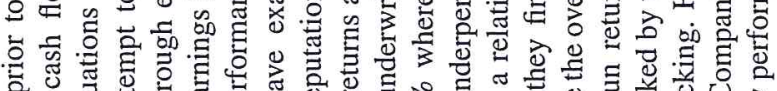

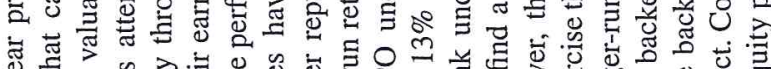

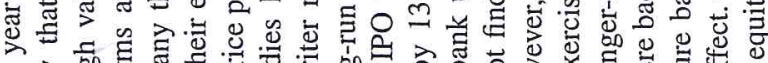

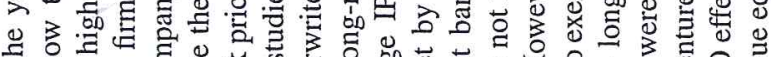

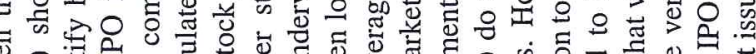

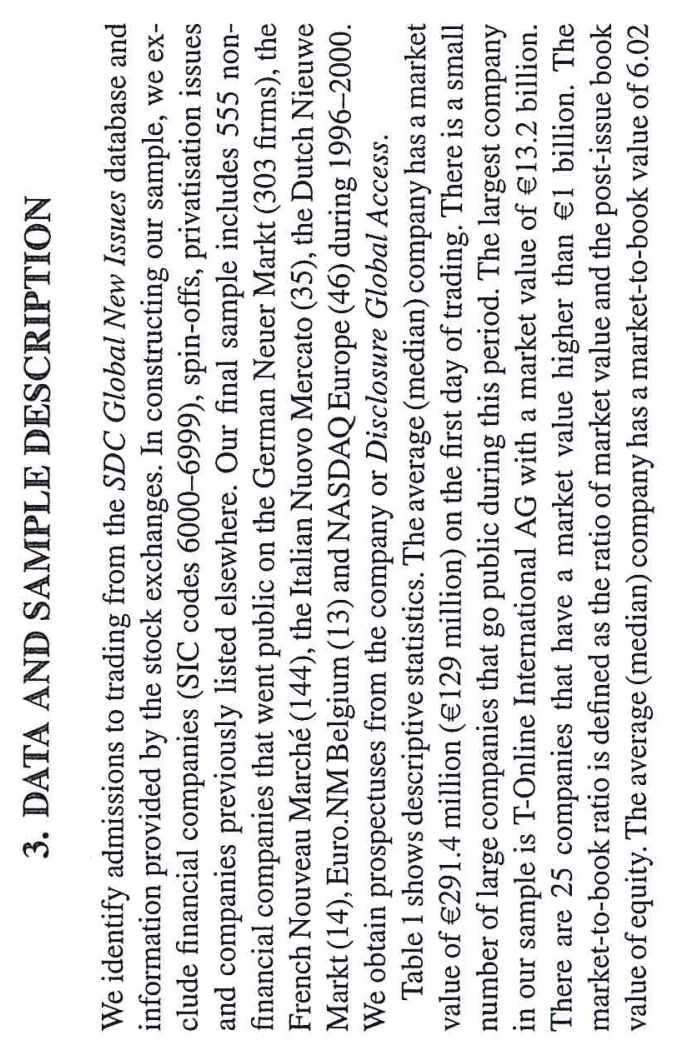

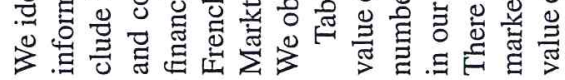

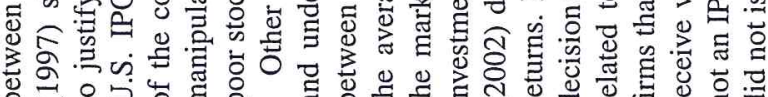

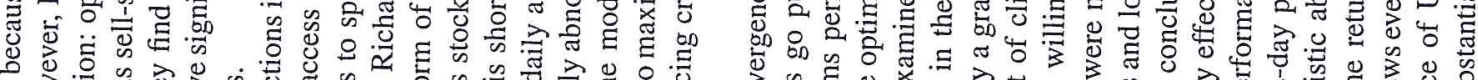

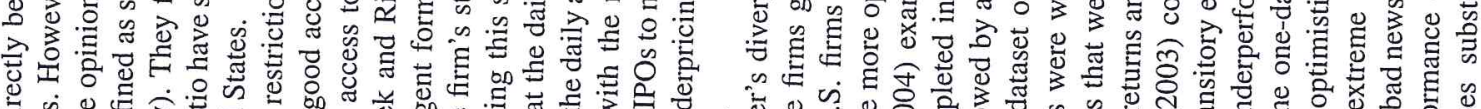

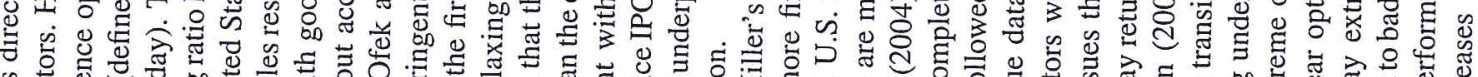

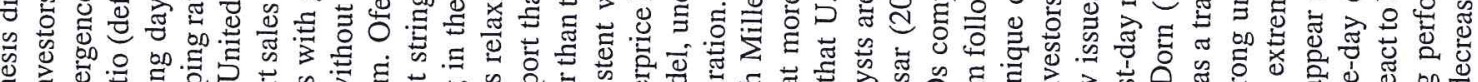

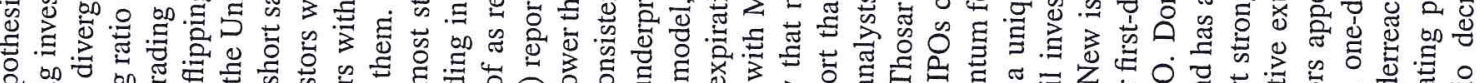

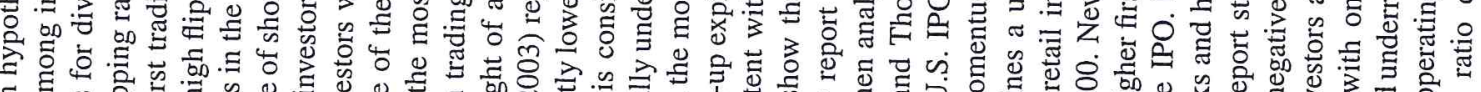

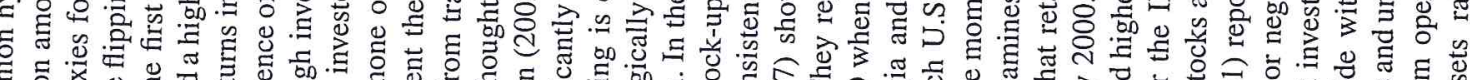

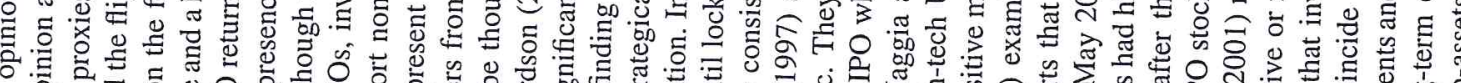

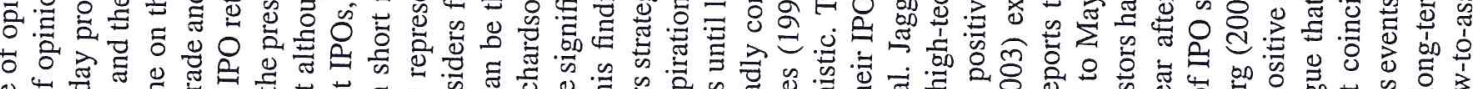

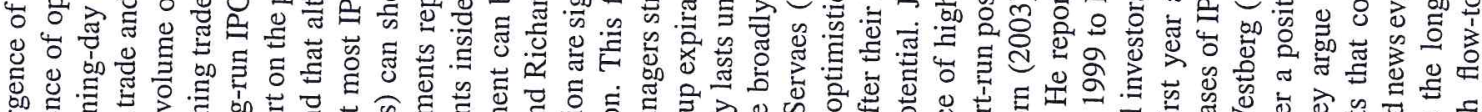

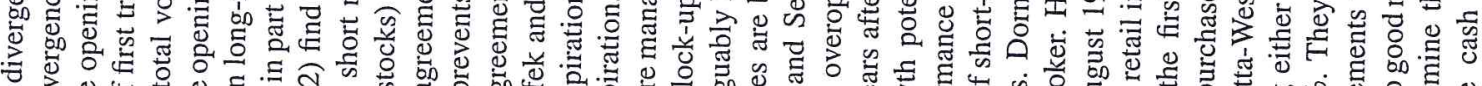

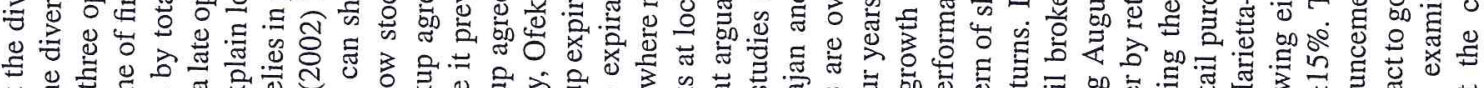

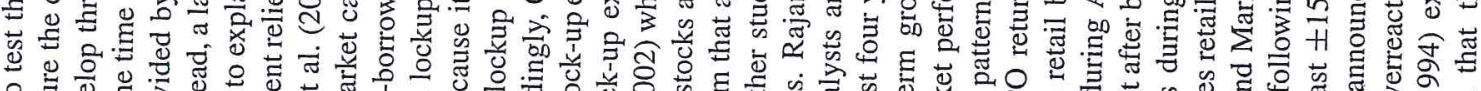
O

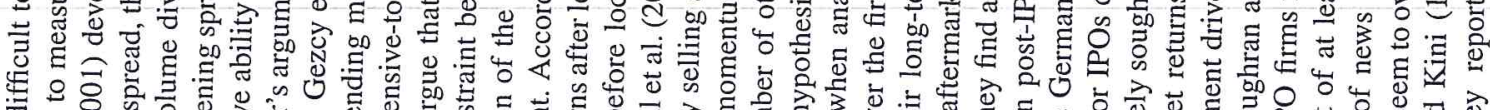

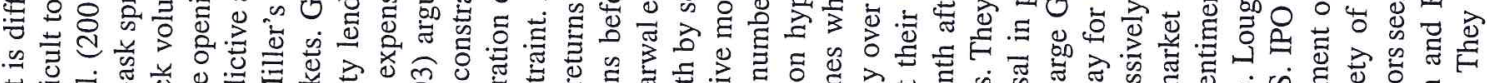

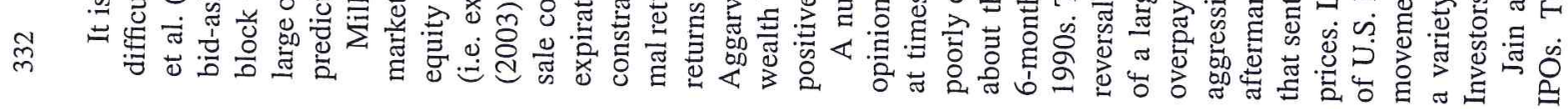




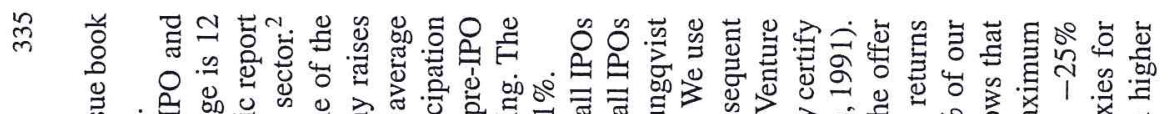

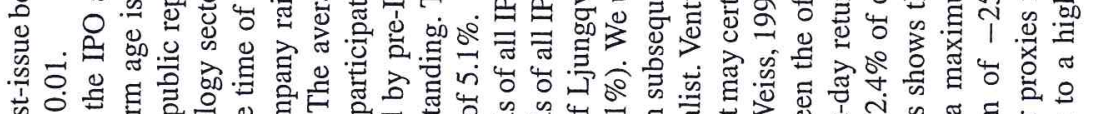

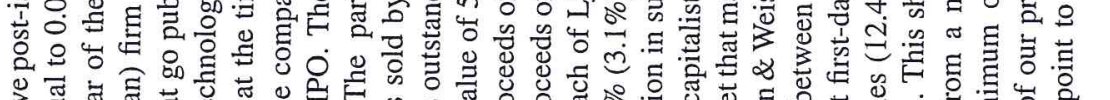

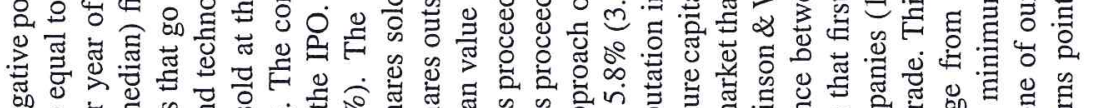

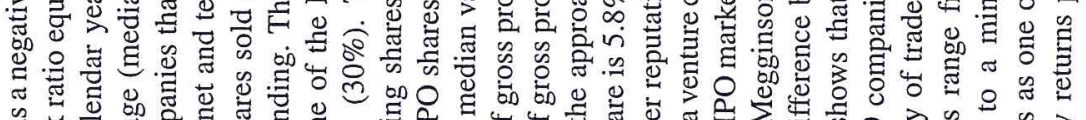

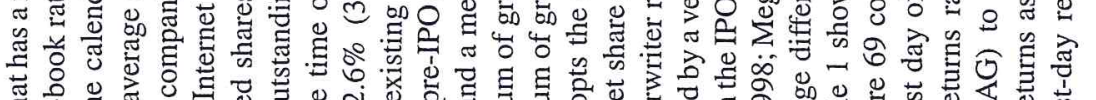

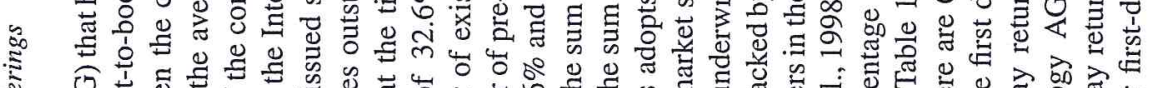

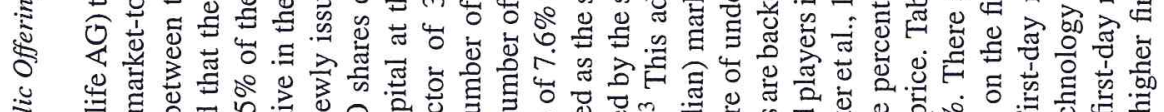

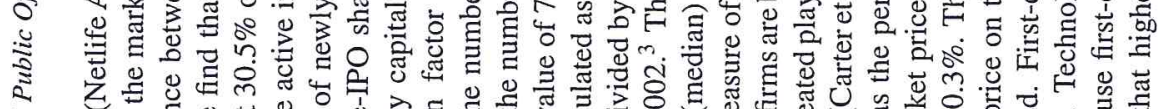

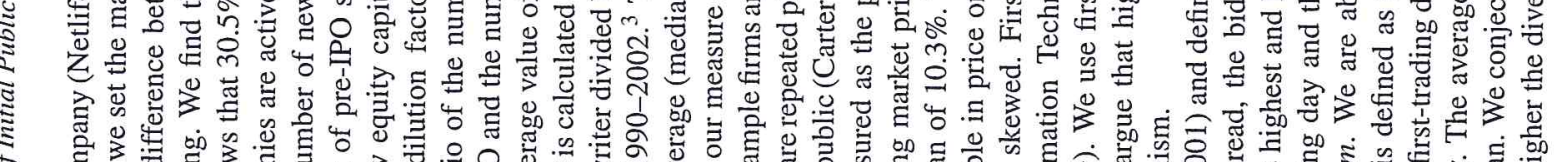

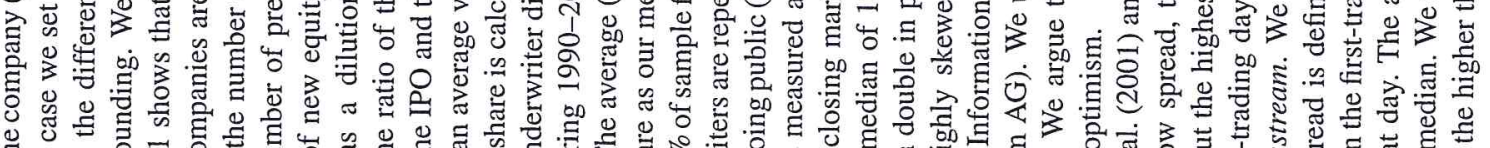

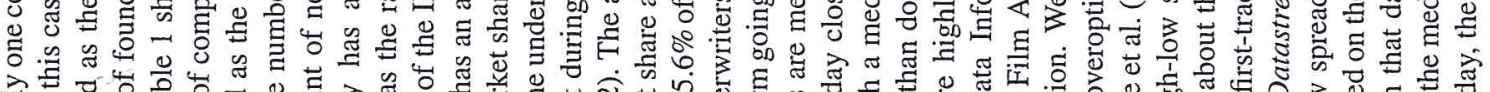

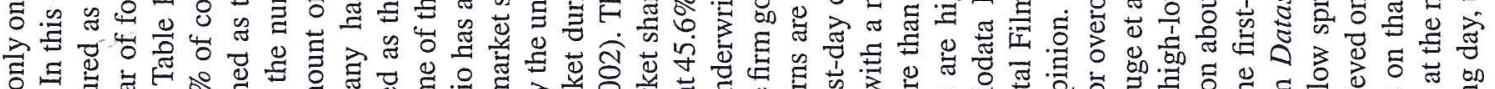

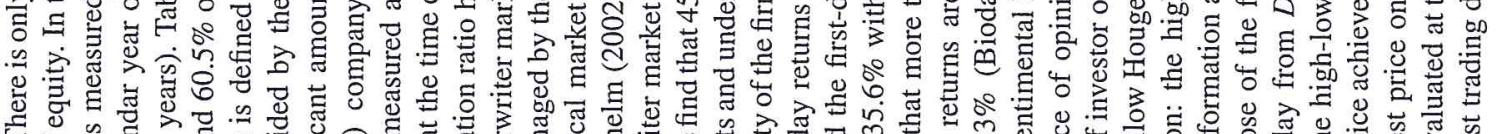

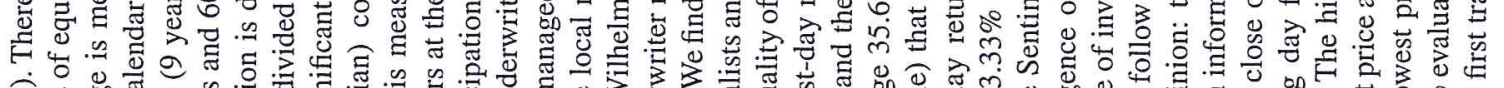

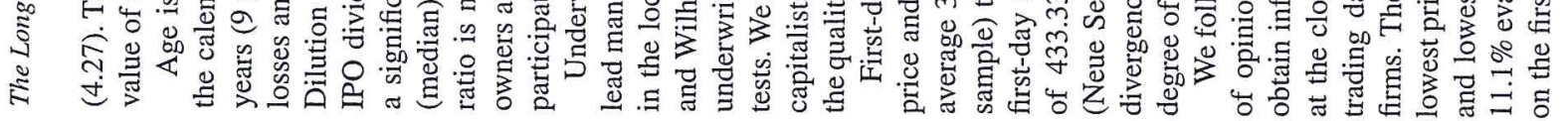

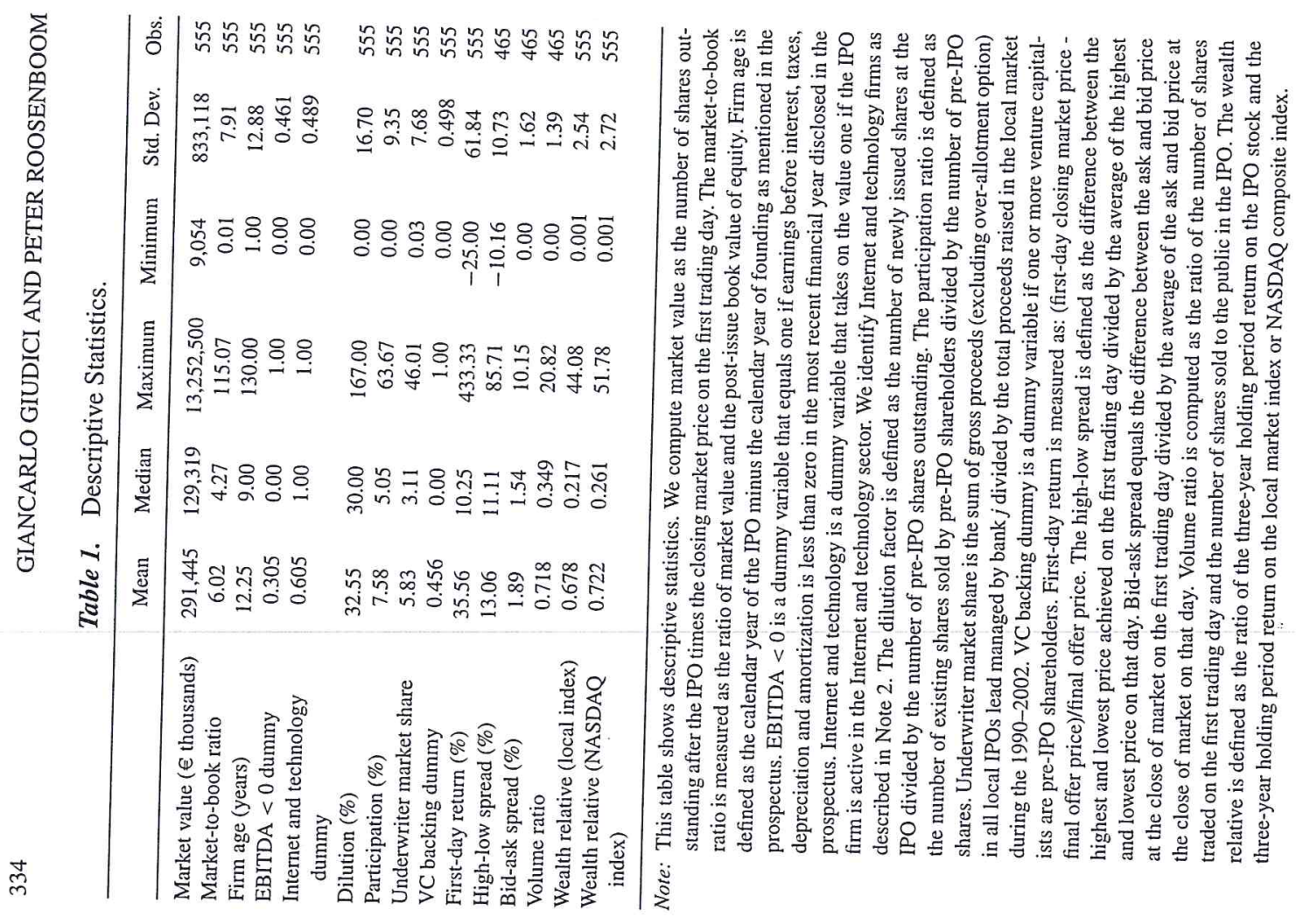




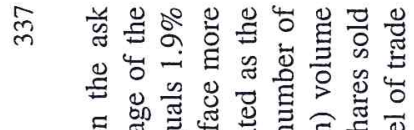

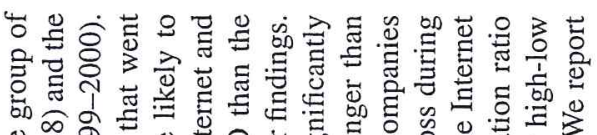

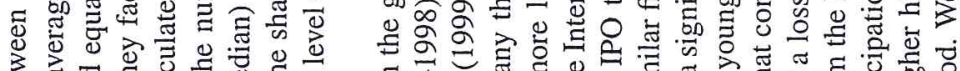

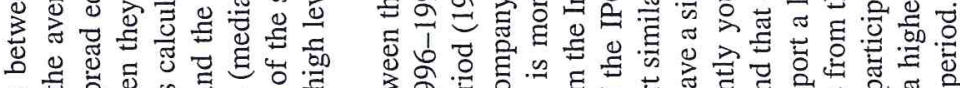
o

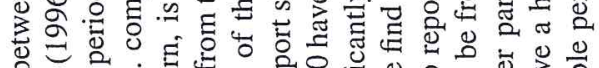

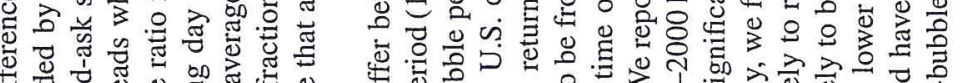

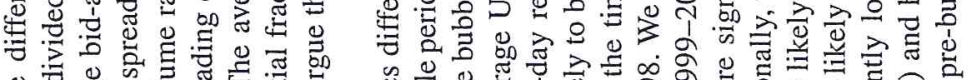

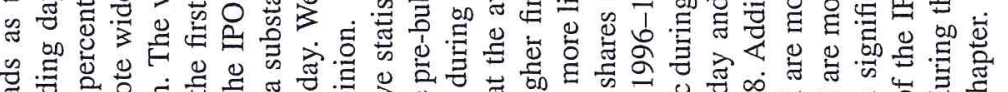

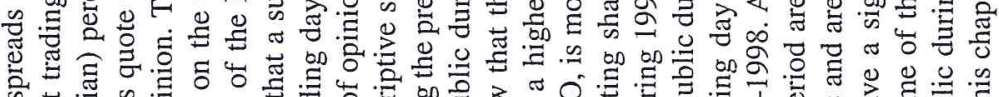

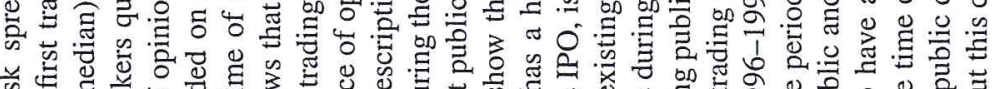

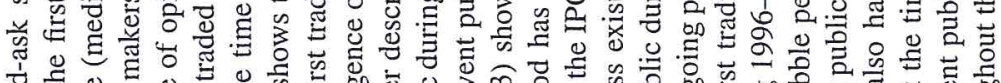

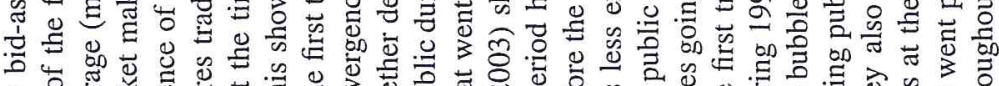

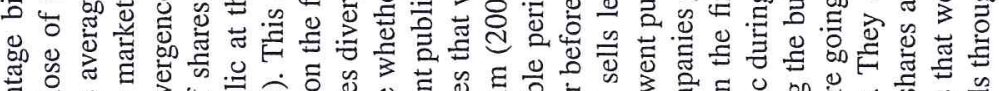

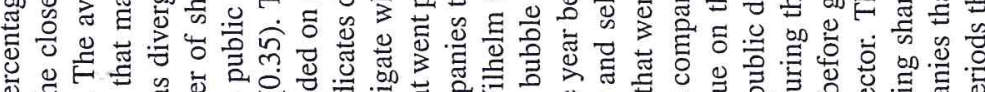

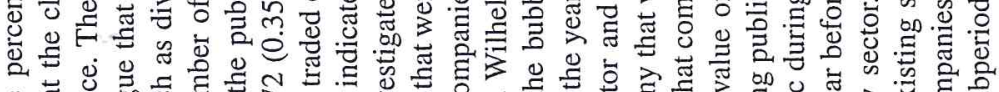

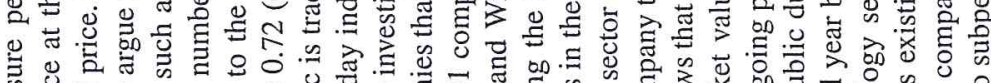

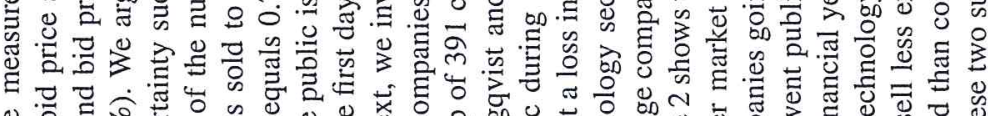

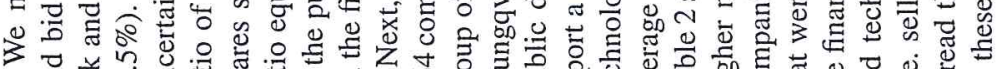

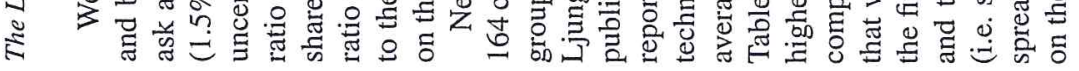
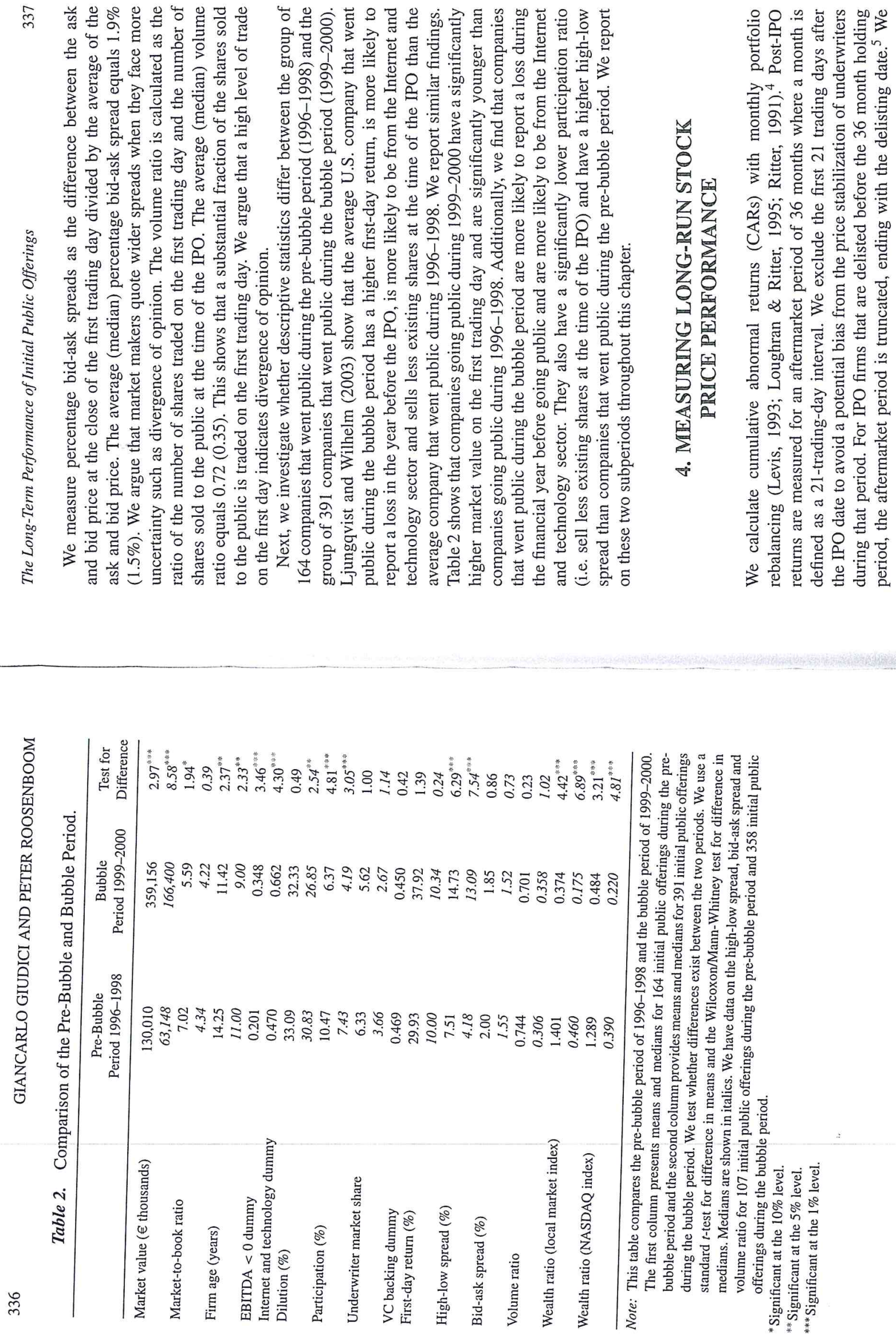


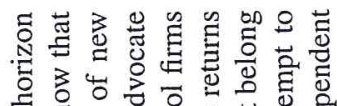

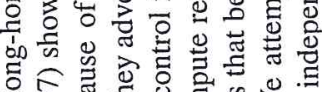

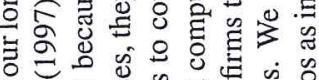

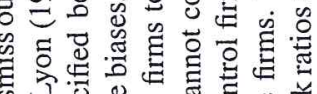

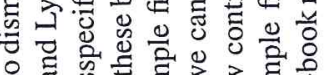

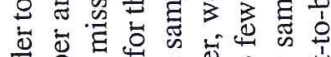

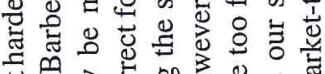

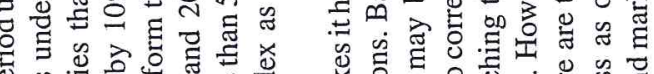

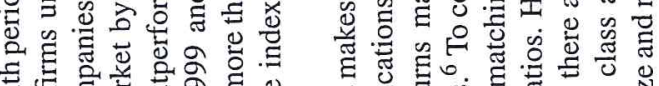

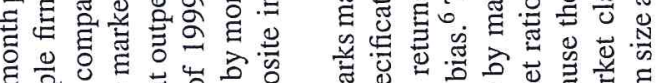

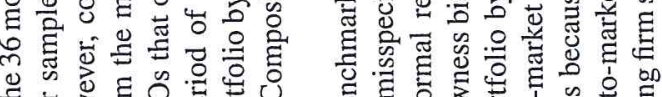
क

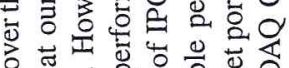

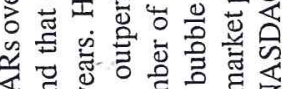

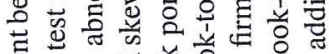

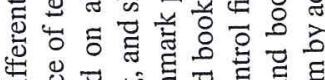

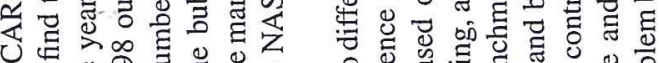

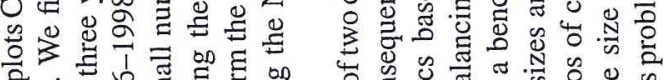

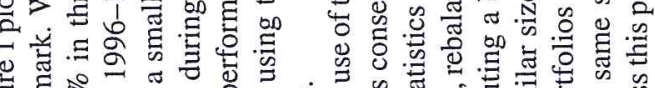

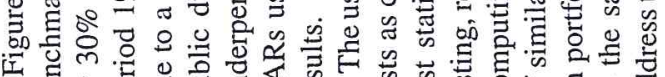

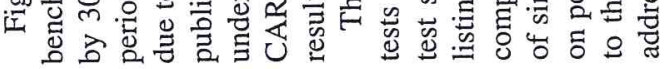
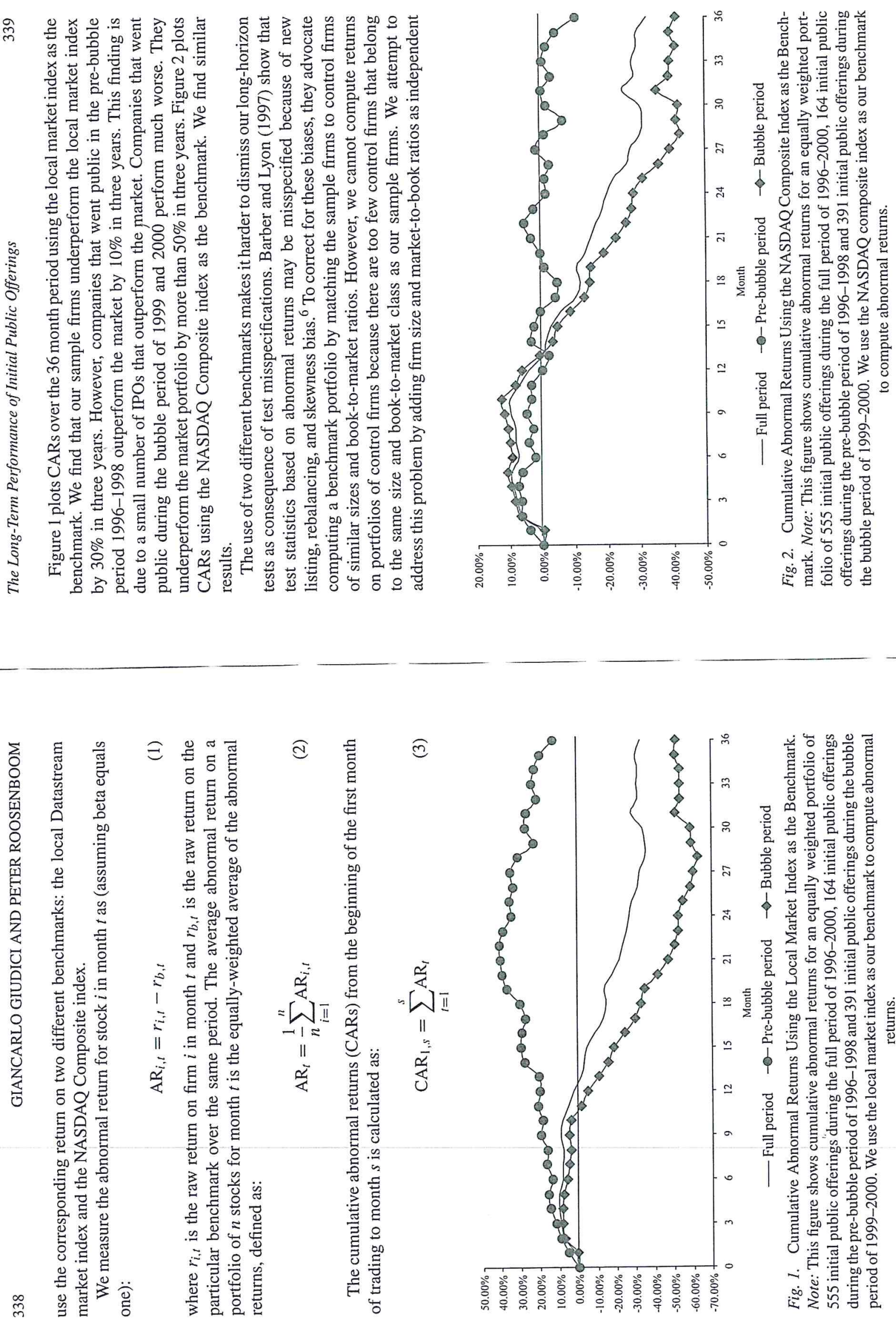

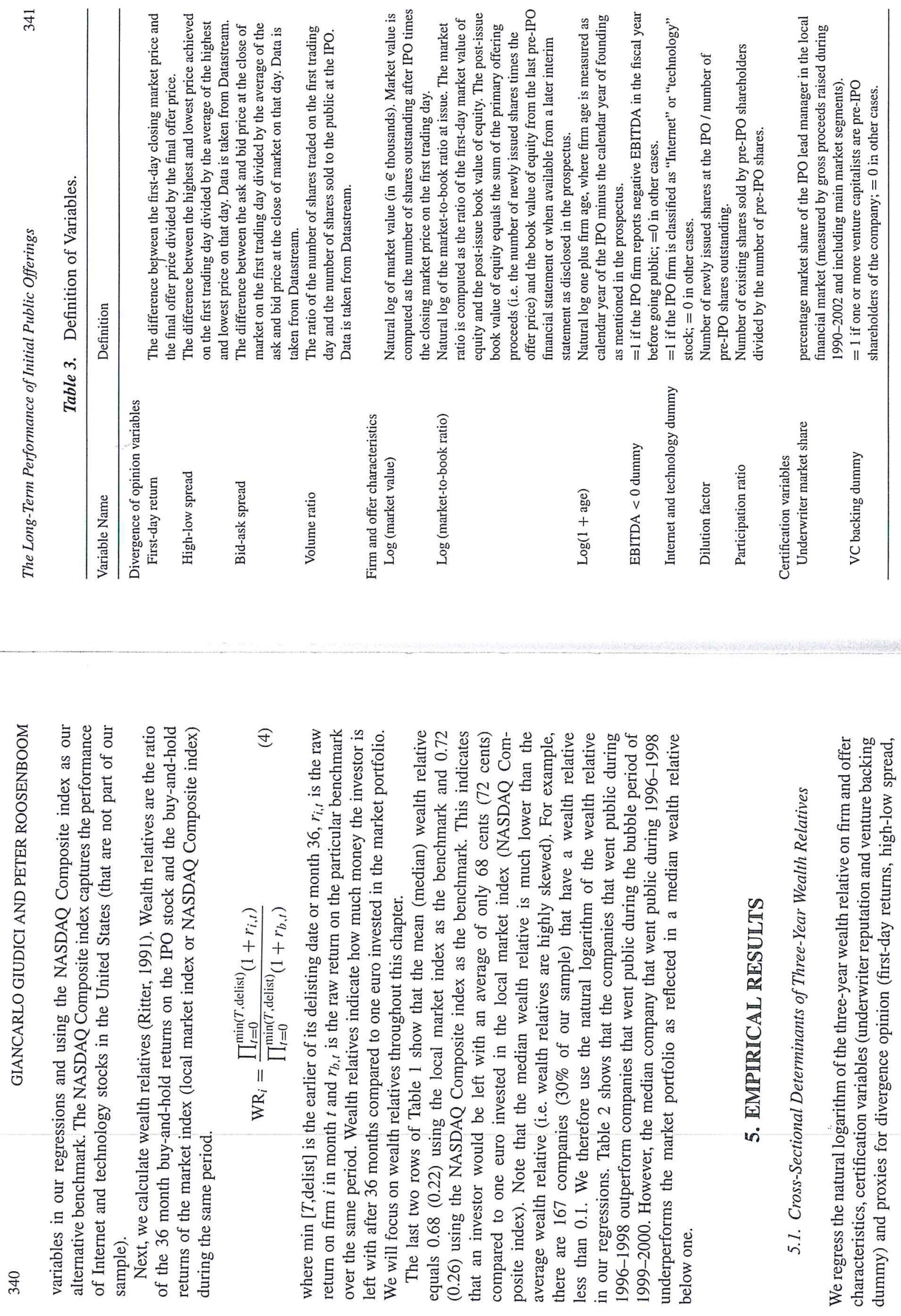


\begin{tabular}{|c|c|c|c|c|c|c|}
\hline$\left(\varepsilon \varepsilon^{*} 0^{-}\right)$ & $\left(29^{\circ} 0\right)$ & $\left(00^{\circ} \mathrm{L}\right)$ & $\left(\downarrow \varepsilon^{\circ} 0^{-}\right)$ & $\left(8 \tau^{\circ} \mathrm{I}\right)$ & $(9 \varepsilon \mathrm{E})$ & \\
\hline ItE.0- & $\varepsilon \varsigma 6^{\circ} 0$ & $\angle 6 L L^{\circ} 0$ & 9๕๕००- & $\nabla S E^{\circ} I$ & $8+60^{\circ}$ & 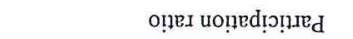 \\
\hline$\left(S I^{*} I\right)$ & $(660)$ & $\left(乙 \subset \cdot 0^{-}\right)$ & $\left(89^{\circ} 0^{-}\right)$ & $\left(\varsigma \tau^{*} 0\right)$ & $\left(8 \varepsilon^{\circ} 0^{-}\right)$ & \\
\hline $\begin{array}{l}198^{\circ} 0^{-} \\
\left(2 \tau^{2} \tau^{-}\right)\end{array}$ & $\begin{array}{l}\text { IEL'0 } \\
\left(I \varepsilon^{*} I-\right)\end{array}$ & LLIOO- & $\varepsilon t t^{\circ} 0-$ & $9 S I^{\circ} 0$ & $89 \mathrm{I}^{\circ} \mathrm{O}^{-}$ & 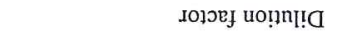 \\
\hline $\begin{array}{l}\left(z z^{2}-\right) \\
\text { osco- }\end{array}$ & $\begin{array}{l}(\text { (IEI-) } \\
\text { †It'0- }\end{array}$ & $\begin{array}{l}=\left(\varepsilon t^{\prime} \tau-\right) \\
97 \varepsilon \cdot 0-\end{array}$ & $\begin{array}{l}(\varsigma \varepsilon \tau-) \\
7 \subseteq \varepsilon \cdot 0-\end{array}$ & $\left(09^{\circ} 0^{-}\right)$ & $\begin{array}{l}(6 t \tau-) \\
67 c 0-\end{array}$ & 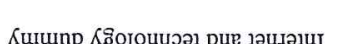 \\
\hline $\begin{array}{l}\text { (9) } \\
\left(9 S^{\circ}-\right)\end{array}$ & $\begin{array}{l}\nabla I \nabla 0^{-} \\
\left(\varepsilon \varsigma^{\circ}\right)\end{array}$ & $\begin{array}{l}9 \tau \varepsilon^{\circ} 0^{-} \\
\left(\varepsilon 6{ }^{\circ}-\right)\end{array}$ & $\begin{array}{l}Z S \varepsilon^{\circ} 0^{-} \\
\left(\varsigma 6^{\circ} I^{-}\right)\end{array}$ & $\left(\tau \tau^{*} \mathrm{I}\right)$ & $\begin{array}{c}\varepsilon \tau \varepsilon 0^{-} \\
\left(I t^{\circ} \tau-\right)\end{array}$ & 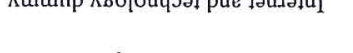 \\
\hline 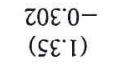 & $\begin{array}{l}\text { SLZ:0- } \\
\left(9 Z^{\circ} 0^{-}\right)\end{array}$ & $\begin{array}{l}t \subseteq \varepsilon \cdot 0- \\
(\tau \neq \cdot I)\end{array}$ & $\begin{array}{l}+9 \varepsilon^{*} 0- \\
\left(I L^{\prime} I\right)\end{array}$ & $\begin{array}{l}8 \angle t^{\circ} 0^{-} \\
\left(I \tau \cdot 0^{-}\right)\end{array}$ & $\begin{array}{l}91 t^{\circ} 0^{-} \\
\left(99^{\circ} \mathrm{l}\right)\end{array}$ & Kurunp $0>$ * \\
\hline $\begin{array}{l}\angle S I^{\circ} 0 \\
\left(S 0^{\circ} I_{-}\right)\end{array}$ & $\begin{array}{l}190^{\circ} 0^{-} \\
\left(01^{\circ} 0^{-}\right)\end{array}$ & $\begin{array}{l}\text { StI.0 } \\
\left(6 Z^{\circ} 0^{-}\right)\end{array}$ & $\begin{array}{l}\angle 8 \mathrm{I}^{\circ} 0 \\
\left(8 \varepsilon^{\circ} 0^{-}\right)\end{array}$ & $\begin{array}{l}0+0^{\circ} 0^{-} \\
\left(08^{\circ} 0^{-}\right)\end{array}$ & $\begin{array}{l}\text { LSI0 } \\
\left(0 I^{\circ} 0\right)\end{array}$ & $(28 \mathrm{c}+\mathrm{I}) \stackrel{\mathrm{0} 0}{ } \mathrm{~T}$ \\
\hline $\begin{array}{l}\text { 6et०0- } \\
(I \tau \cdot I-)\end{array}$ & $\begin{array}{l}870^{\circ} 0^{-} \\
\left(s+0^{-}\right)\end{array}$ & $\begin{array}{l}\angle 80^{\circ} 0^{-} \\
\left(\varepsilon \nabla^{\circ} C^{-}\right)\end{array}$ & $\begin{array}{l}D I I^{\circ} 0^{-} \\
\left(s t I^{-}\right)\end{array}$ & $\begin{array}{l}\varepsilon \succ \varepsilon 0^{-} \\
\left(\varepsilon \tau^{\circ} 0^{-}\right)\end{array}$ & $\begin{array}{l}+20^{\circ} 0 \\
\left(88^{\circ} \tau-\right)\end{array}$ & 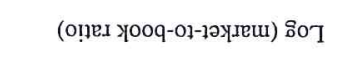 \\
\hline$\nabla z I^{\circ} 0^{-}$ & $260^{\circ} 0^{-}$ & $\downarrow I Z 0^{\circ}-$ & ఒ६เ००- & $\varepsilon \varepsilon 0^{\circ}-$ & $\forall\left[Z^{\circ} 0^{-}\right.$ & 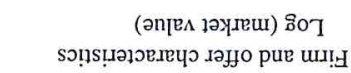 \\
\hline$(\varsigma+0)$ & $\left(\angle 60^{\circ}\right)$ & $\left(\mathrm{II}^{*} \mathrm{I}\right)$ & & & & \\
\hline $\begin{array}{l}910^{\circ} 0 \\
\left(00^{\circ} I^{-}\right)\end{array}$ & $\begin{array}{l}\varepsilon 80^{\circ} 0 \\
\left(\tau 8^{\circ} 0^{-}\right)\end{array}$ & $\begin{array}{l}8 \varepsilon 0^{\circ} 0 \\
\left(\mathrm{ZL} L^{\circ}-\right)\end{array}$ & & & & o!̣es әuпโо \\
\hline $\begin{array}{l}9 S \varepsilon^{\prime} I- \\
\left(09^{\circ} 0^{-}\right)\end{array}$ & $\begin{array}{l}8 \varepsilon I^{\circ} 9- \\
\left(9 \varsigma 0^{-}\right)\end{array}$ & $\begin{array}{l}8 \subseteq 60^{\circ}- \\
\left(\varepsilon L^{\circ} I^{-}\right)\end{array}$ & & & & praIds yse-p!g \\
\hline $\begin{array}{l}6\left\llcorner 6^{\circ} 0^{-}\right. \\
\left(\subseteq 6^{\circ} I^{-}\right)\end{array}$ & $\begin{array}{l}0+I^{*} I^{-} \\
\left(\varsigma C^{\circ} 0\right)\end{array}$ & $\begin{array}{l}\forall Z 9^{\circ} I^{-} \\
\left.(\varepsilon 6)^{\circ}-\right)\end{array}$ & $\left(L L^{\prime} \mathcal{E}-\right)$ & $\left(8 S^{\prime} 0^{-}\right)$ & $\left(\angle 9^{\circ} \varepsilon-\right)$ & pradds MOI-Чळิ!!H \\
\hline $0 S+0-$ & $160^{\circ} 0$ & $86 \varepsilon 0^{\circ-}$ & $889^{\circ} 0-$ & $900^{\circ} 0-$ & 9\&9.0- & 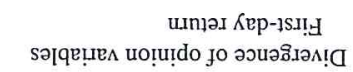 \\
\hline 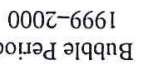 & 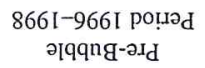 & $\begin{array}{l}000 z-966 \mathrm{I} \\
\text { po!̣әd IIn }\end{array}$ & $\begin{array}{l}000 \tau-666 \mathrm{I} \\
\text { po!..2. }\end{array}$ & 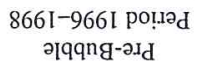 & $\begin{array}{l}0002-966 I \\
\text { poụd I[n] }\end{array}$ & \\
\hline
\end{tabular}

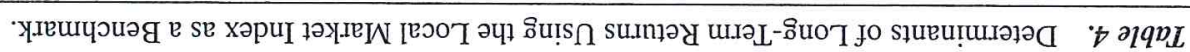

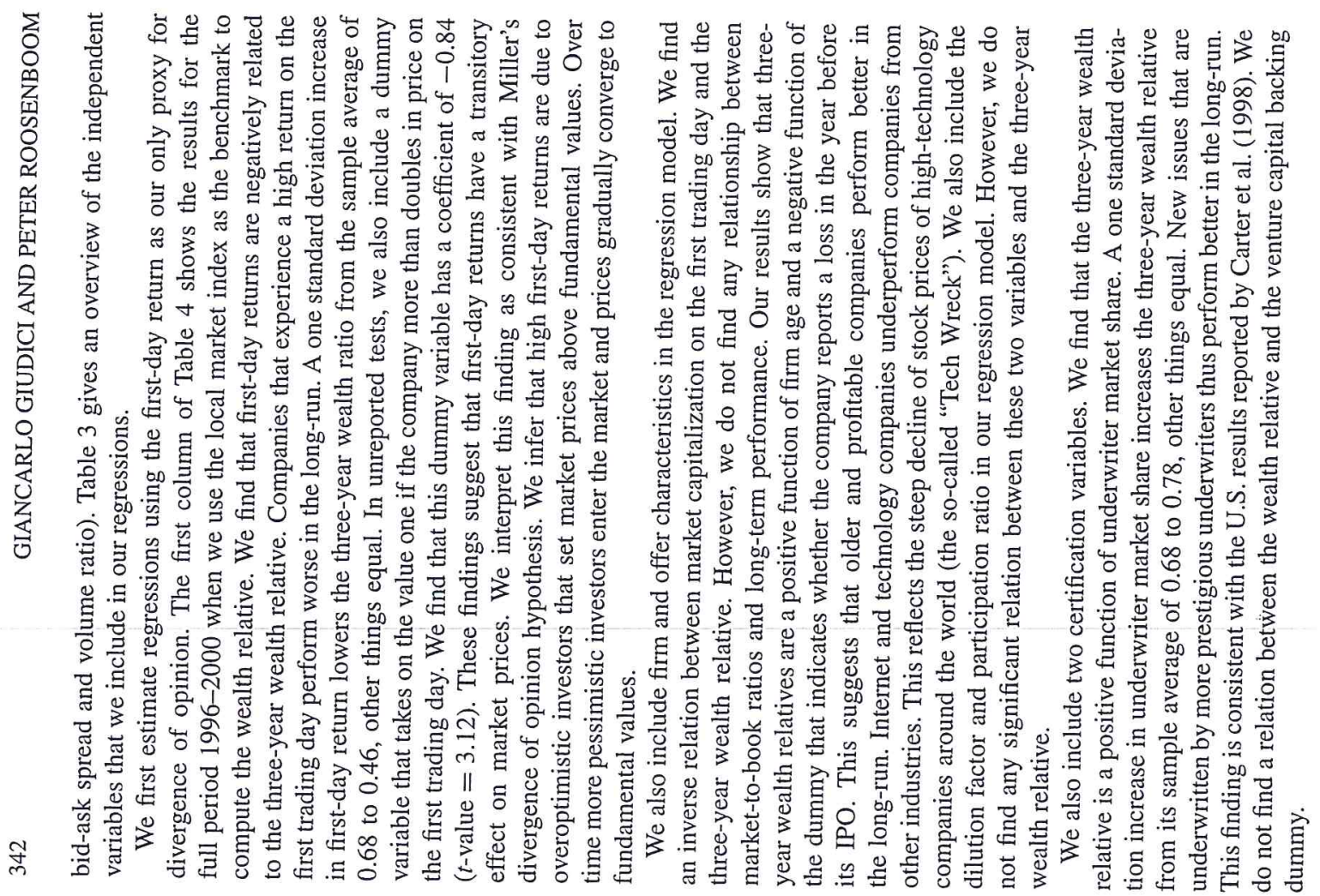



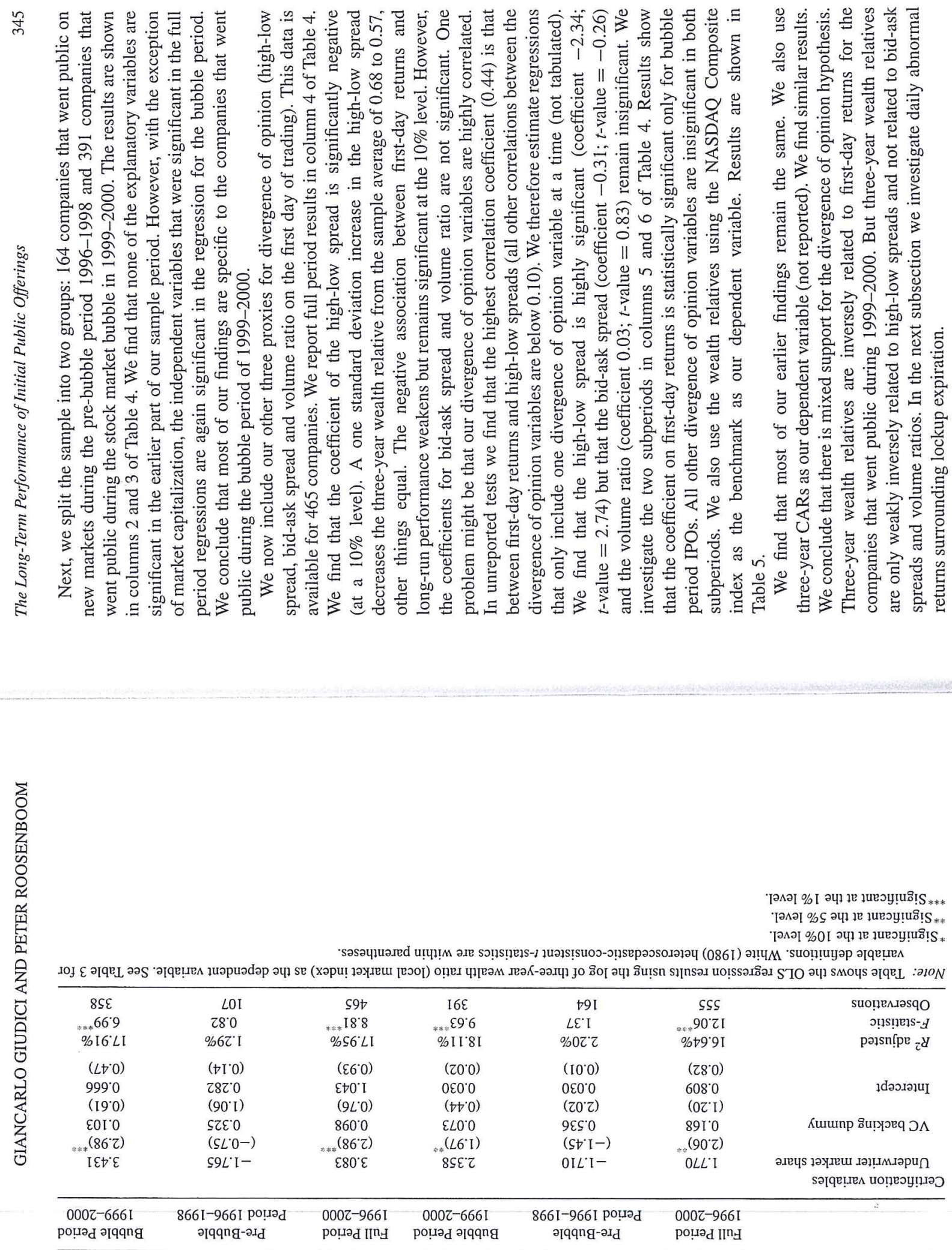

(рәпипио弓) † ว1qрL 


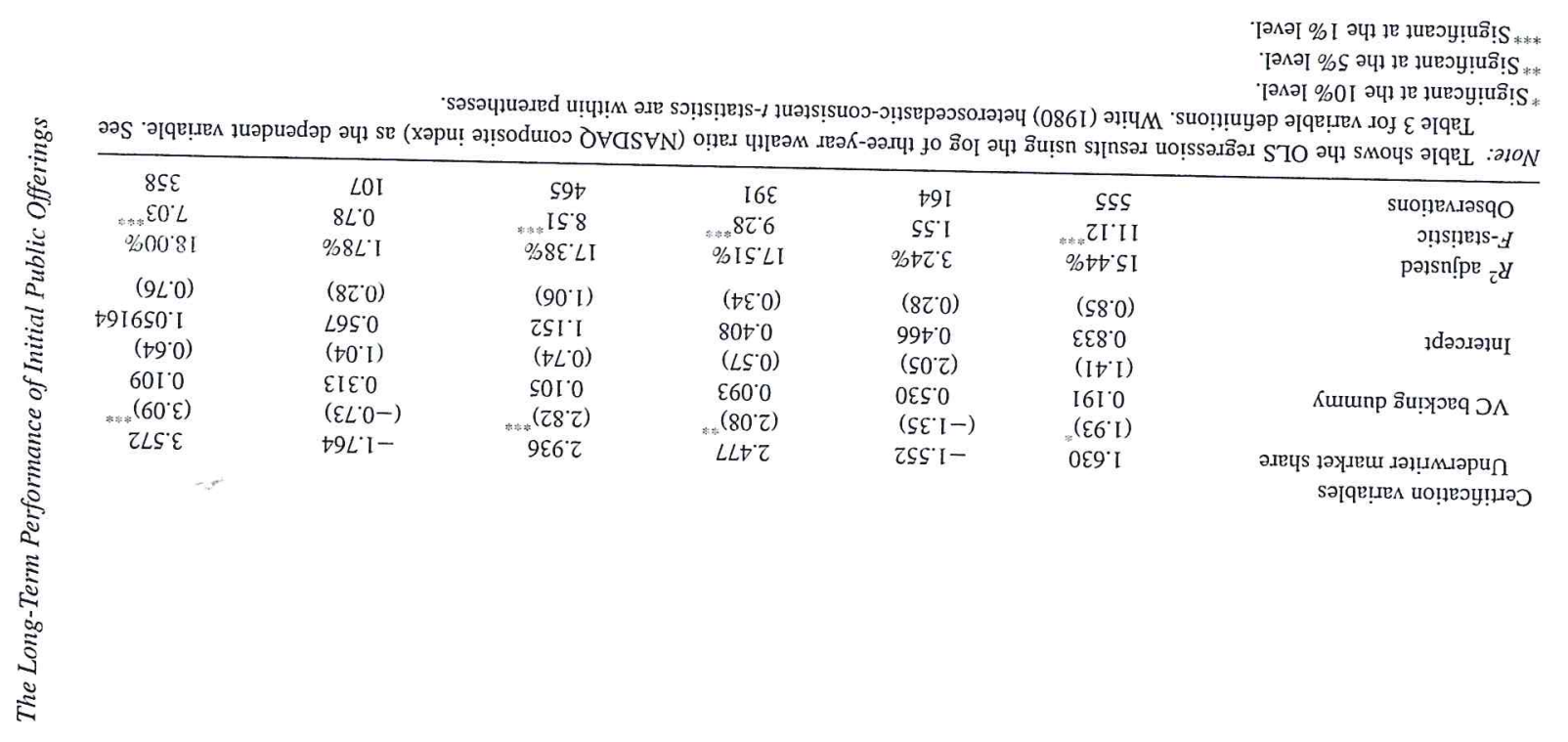

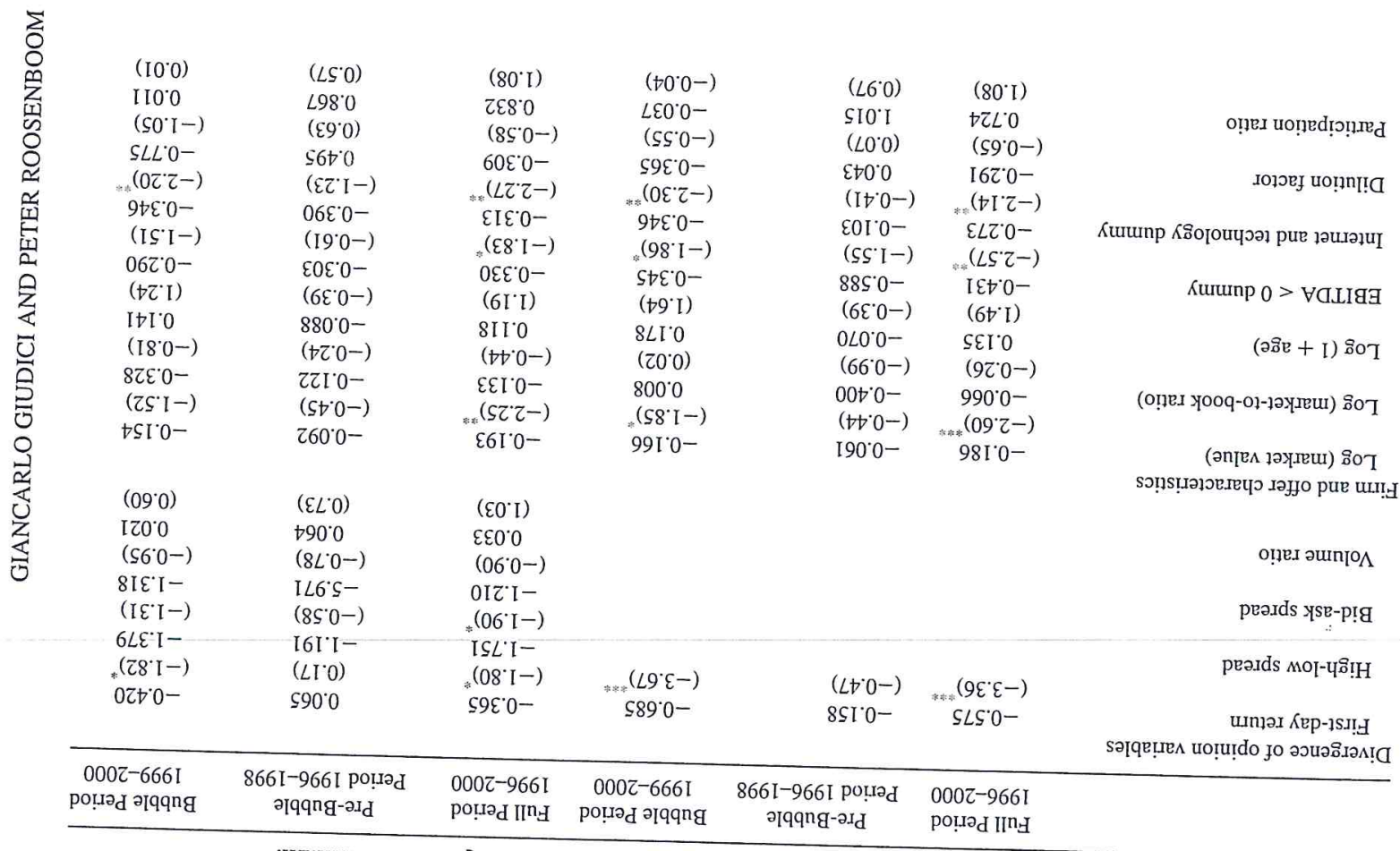




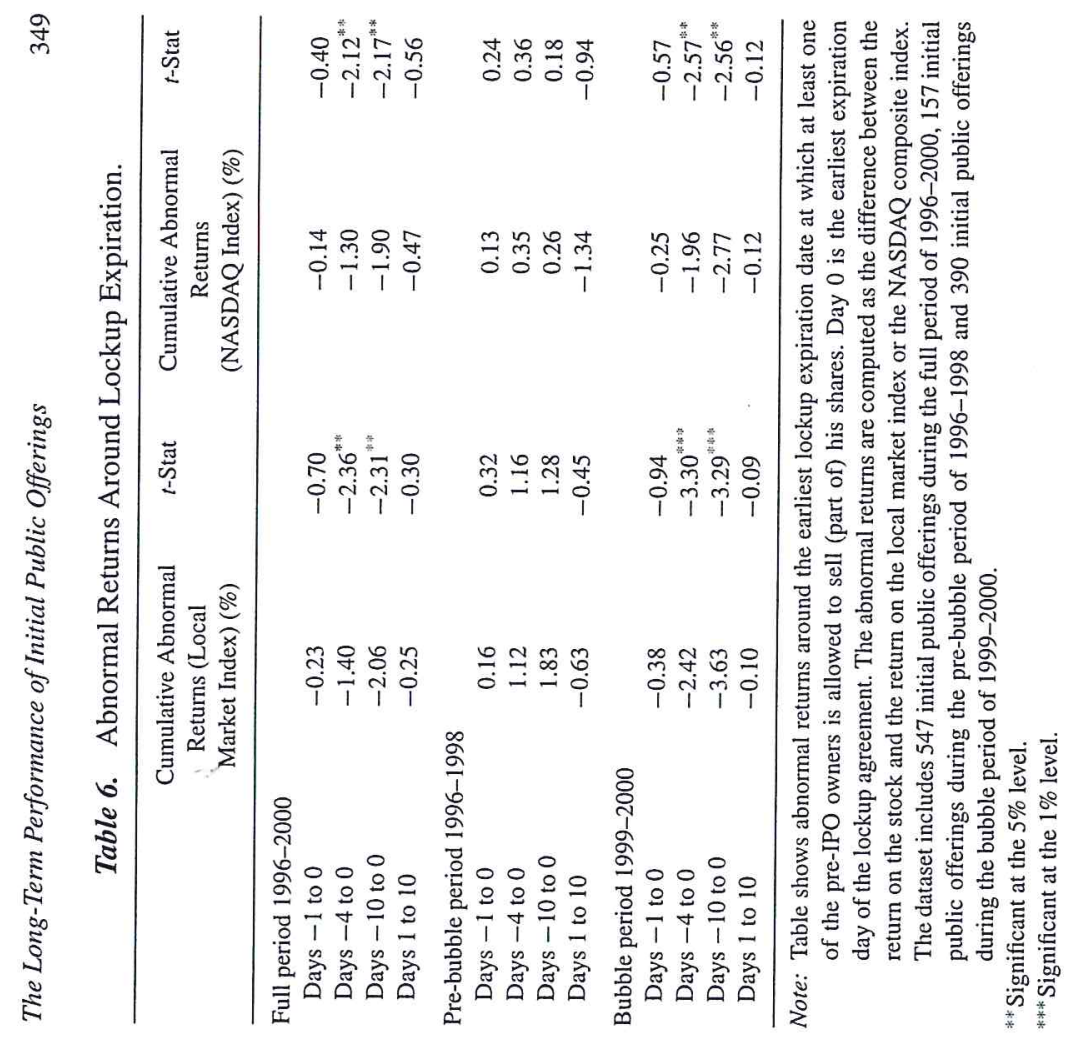

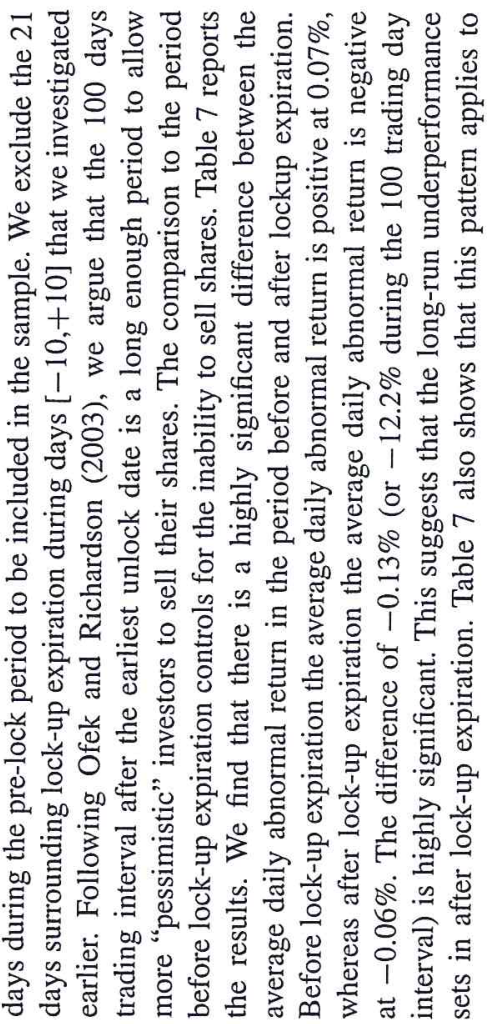

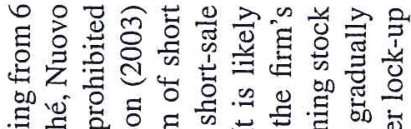

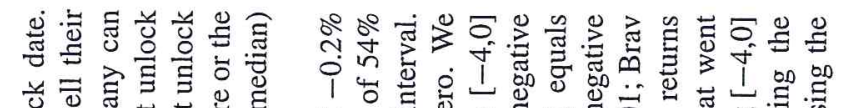

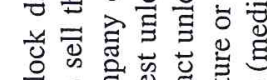

总离离

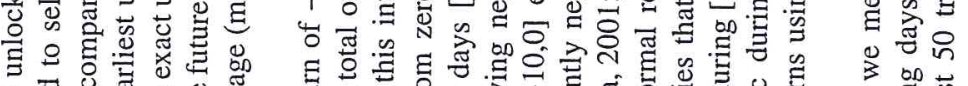

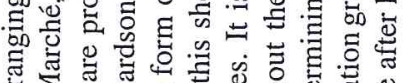

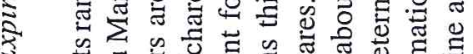

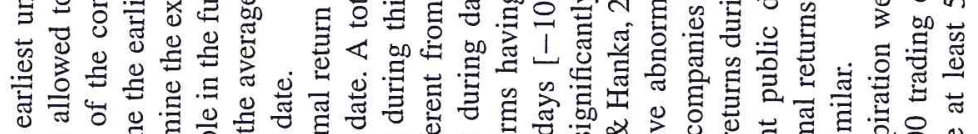

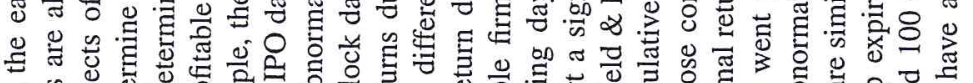

on 0

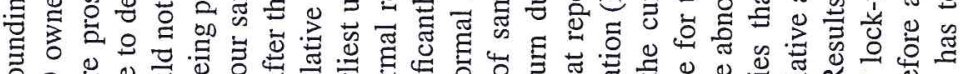

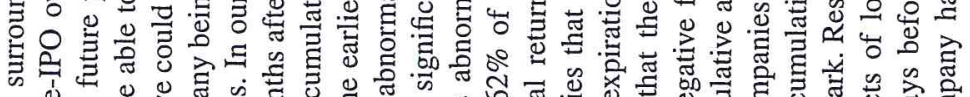

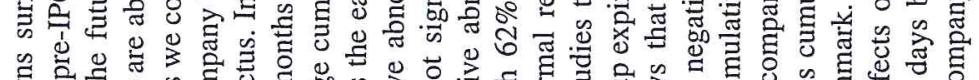

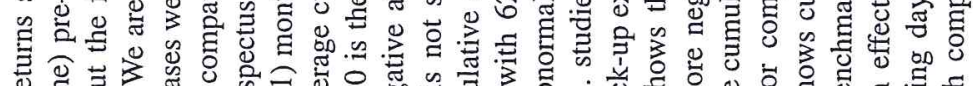

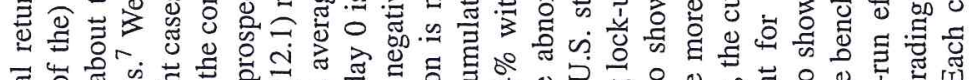

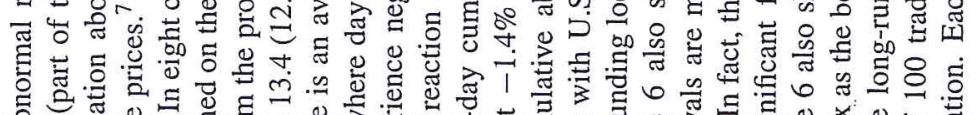

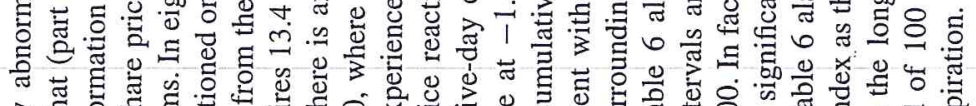

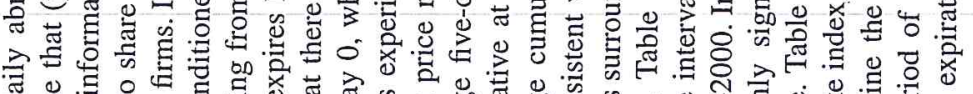

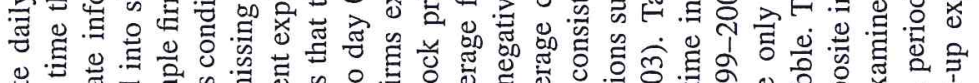

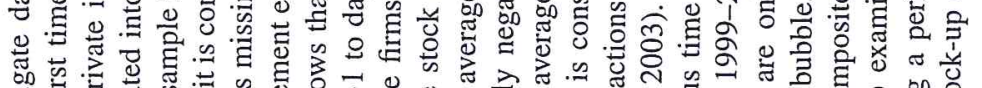

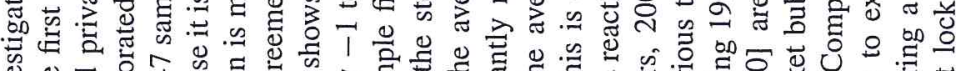

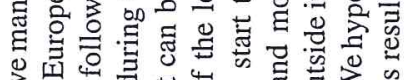

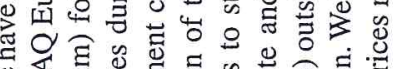

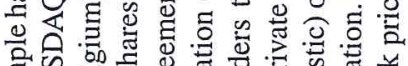

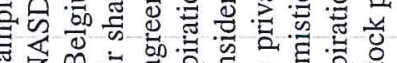

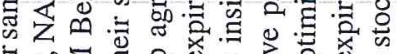

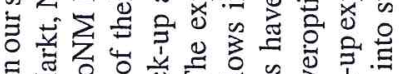
¿

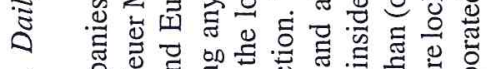

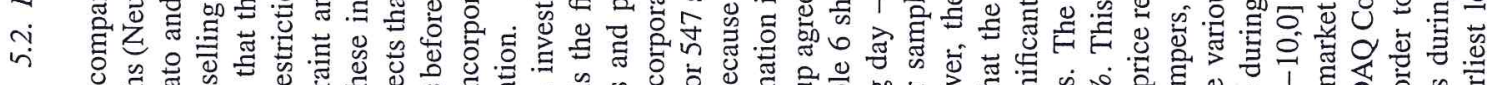

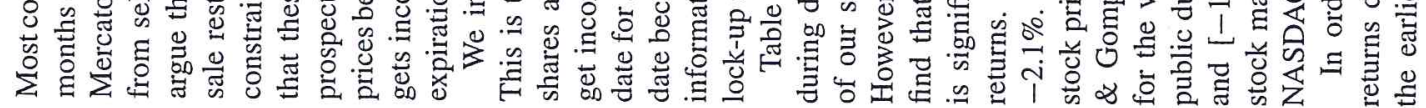




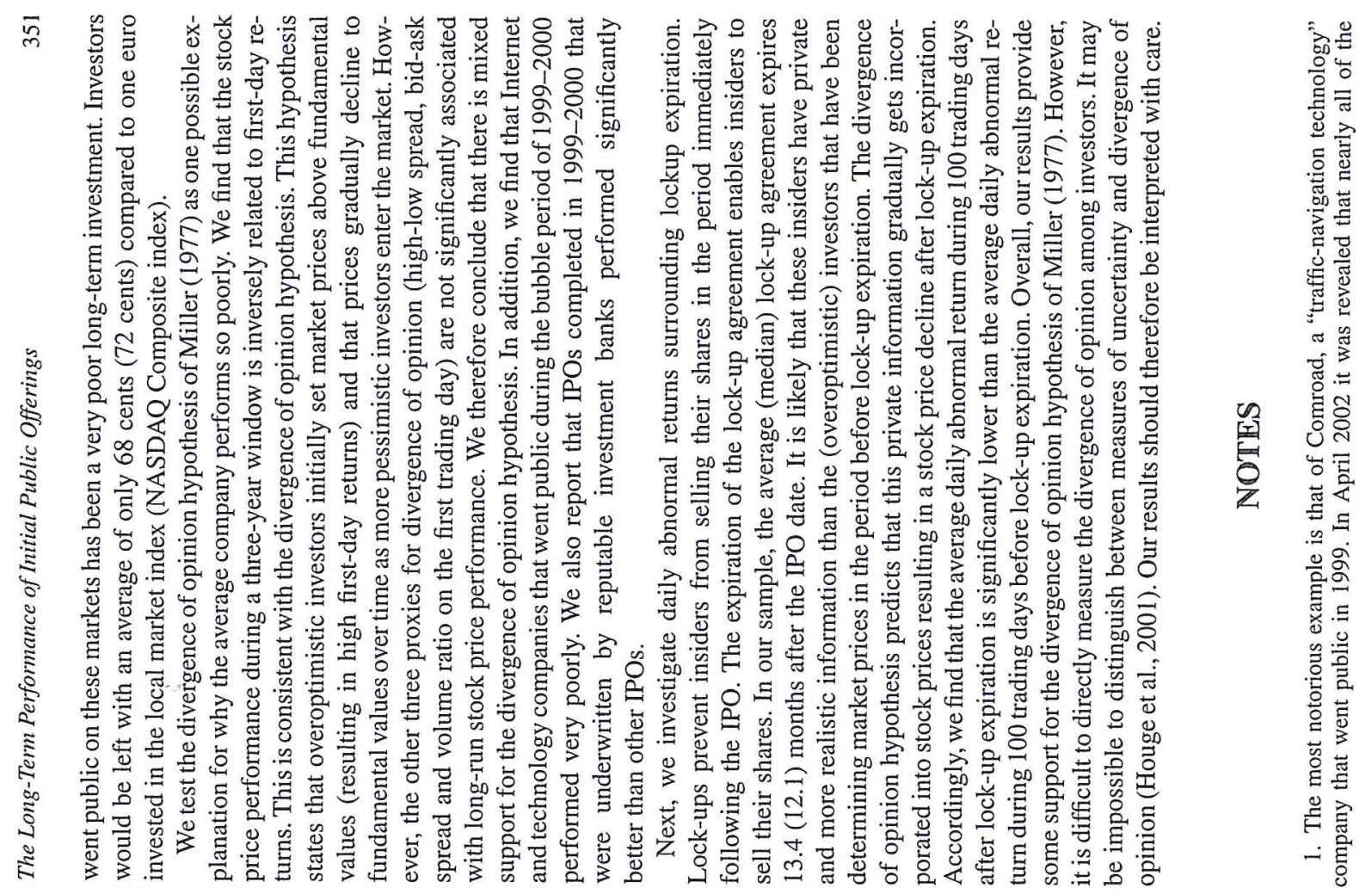

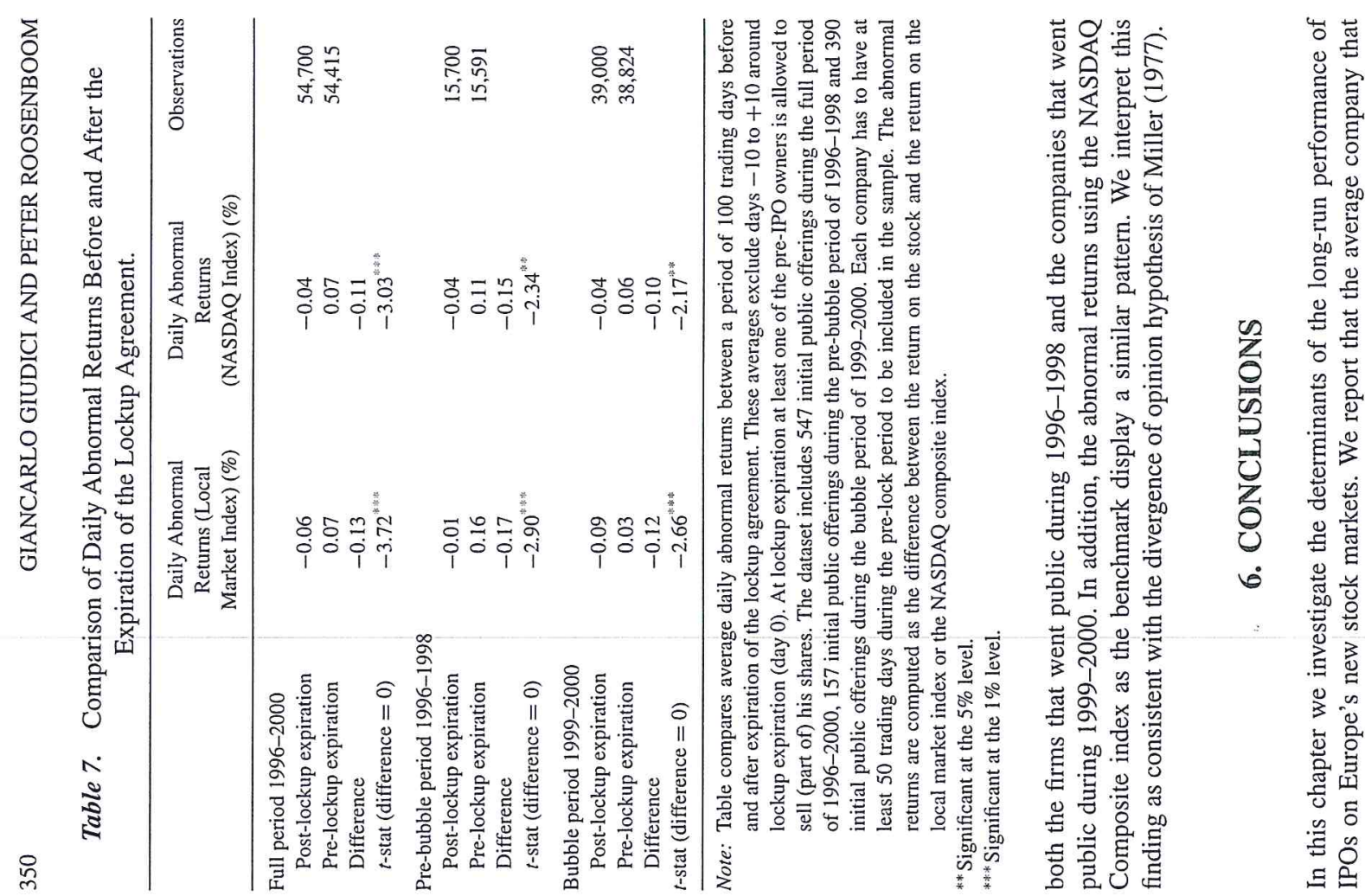



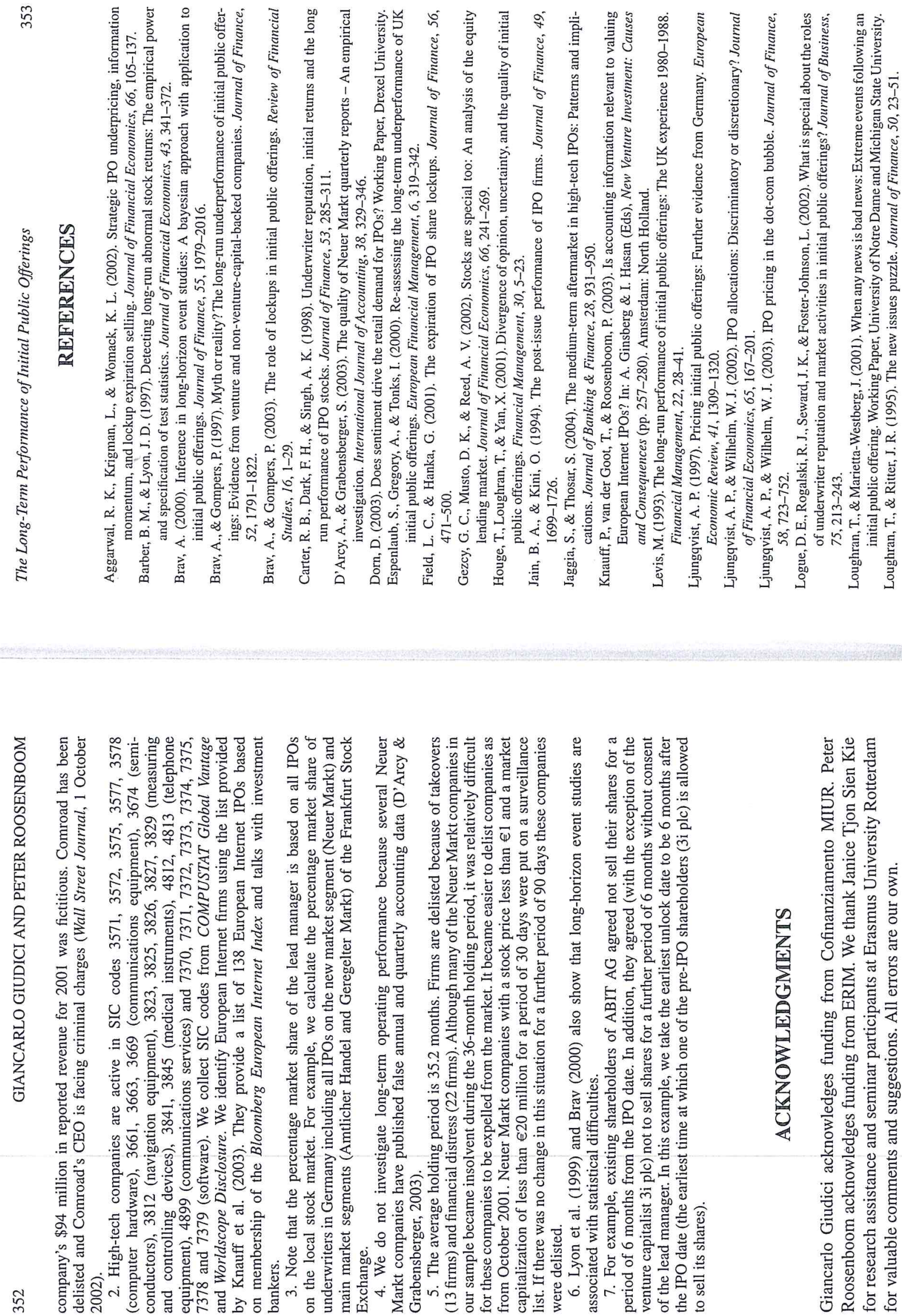


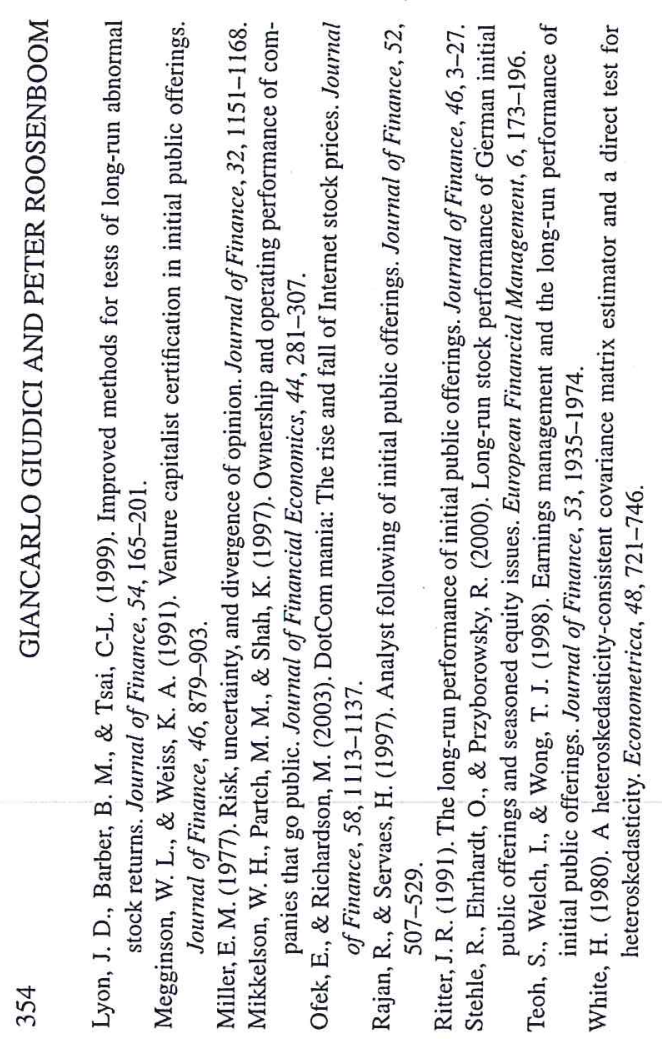

